\title{
LA FRAGMENTACIÓN DEL DERECHO INTERNACIONAL. ¿RIESGOS U OPORTUNIDADES PARA MÉXICO?*
}

\begin{abstract}
Alejandro RODILES**
RESUMEN: La conclusión de los trabajos sobre "fragmentación" por parte de la Comisión de Derecho Internacional no agotó el debate. A la fecha, la discusión sigue dividiéndose entre quienes ven en ella un riesgo para la coherencia del orden jurídico internacional, y aquéllos quienes hablan de un fenómeno acorde a los tiempos que vivimos, que permite al derecho internacional responder de manera más enfocada a los nuevos riesgos globales. Y ante ello, ¿qué deberíamos opinar en México? Tras presentar un panorama general sobre las diferentes posturas que existen al respecto, el presente artículo brinda algunas reflexiones desde una perspectiva mexicana.
\end{abstract}

ABSTRACT: The debate on "fragmentation" has not been exhausted with the conclusion of the International Law Commission's work on the subject. To present, discussions are still divided between those who see in it a threat to the coherence of the international legal order, and those who rather speak of a phenomenon that goes along with our times, allowing international law to deal with global risks in a more focused way. But, what do we have to say to all this in Mexico? After rendering a general overview of different, existing positions, the present article offers some reflexions from a Mexican perspective.

RÉSUMÉ: Le fait que la Commission de Droit International ait conclu ses travaux sur la fragmentation du droit international ne signifie pas que le débat sur ce sujet soit clos. Encore maintenant, le débat oppose ceux que pensent que la fragmentation représente un risque pour la cohérence de l'ordre juridique international à ceux qui la considèrent comme un phénomène d'actualité qui permet au droit international de réagir de façon plus précise face aux menaces mondiales. Dans ce contexte, quelle position devrait être assumée par le Mexique? Après un aperçu général des différentes positions adoptées sur ce sujet, cet article offre quelques réflexions sous une perspective mexicaine.

* Artículo recibido el 29 de julio de 2008 y aceptado para su publicación el 3 de septiembre de 2008.

** Candidato a doctor en derecho en el Instituto de Derecho Internacional de la Universidad Ludwig-Maximilians de Munich, Alemania. El presente artículo está basado en una conferencia impartida junto con el embajador Joel Hernández, consultor jurídico de la Secretaría de Relaciones Exteriores, el 30 de enero de 2008, en el Centro de Investigación y Docencia Económica (CIDE), Santa Fe, ciudad de México. El autor agradece al embajador Hernández por un estimulante intercambio de ideas, así como a Guillaume Michel por el résumé. Las opiniones vertidas en el presente artículo y los errores en él contenidos son la única y exclusiva responsabilidad del autor. 
SUMARIO: I. A manera de introducción. Un pequeño recuento. II. Panorama doctrinario. III. La fragmentación y México. Algunas reflexiones finales.

\section{A MANERA DE INTRODUCCIÓN. UN PEQUEÑO RECUENTO}

La fragmentación del derecho internacional ha sido una preocupación teórica, por lo menos, desde mediados del siglo pasado, destacándose desde entonces la ramificación que viviría el derecho internacional a raíz de los múltiples regímenes normativos creados por tratados multilaterales de diversa índole material (funcional) y regional. ${ }^{1}$ Un argumento plausible y de fácil constatación, si observamos cómo ciertos tratados han dado lugar, mediante el establecimiento de instituciones encargadas del desarrollo normativo posterior de sus disposiciones materiales generales, ${ }^{2}$ a lo que hoy denominamos "sistema universal de derechos humanos" y sus vertientes continentales, o bien, al "derecho comunitario europeo", por mencionar sólo los casos más conocidos.

1 Este argumento fue articulado por Wilfried Jenks en un conocido artículo de 1953, que es retomado por la Comisión de Derecho Internacional (CDI) en su informe final sobre el tema. Cfr. Jenks, Wilfried, "The Conflict of Law-MakingTtreaties", British Yearbook of International Law (BYIL), vol. 30, 1953, pp. 401-453; citado por CDI, 58o. periodo de sesiones, Fragmentación del Derecho Internacional: Dificultades Derivadas de la Diversificación y Expansión del Derecho Internacional, Informe del Grupo de Estudio de la CDI, elaborado por Martti Koskenniemi, A/CN.4/L.682, 13 de abril de 2006, párs. 5 y ss.

2 De ahí que también podamos hablar de "tratados-marco", en el sentido de que dichos acuerdos multilaterales contienen lineamientos generales a ser desarrollados posteriormente por órganos para ello establecidos en los mismos tratados. Dicho desarrollo normativo puede darse mediante órganos de monitoreo, como el Comité de Derechos Humanos, instituido por el Pacto Internacional de Derechos Civiles y Políticos, así como por medio de tribunales encargados de aplicar e interpretar las normas de los tratados, tal es el caso de la Corte Interamericana de Derechos Humanos (CIDH), creada para tales fines por el Pacto de San José, o bien en virtud de auténticos órganos legislativos, como el Consejo de la Unión Europea (UE) y el Parlamento Europeo, cuyas facultades legislativas se encuentran estipuladas principalmente en el Tratado Constitutivo de la Comunidad Europea. En los sistemas más desarrollados, como el comunitario europeo, contamos con la presencia de órganos tanto legislativos como jurisdiccionales (el Tribunal de Justicia de las Comunidades Europeas o TJCE) y ejecutivos (Comisión Europea y, hasta cierto punto, el Consejo de la UE). 
No fue, empero, sino hasta mediados de los noventa cuando la "fragmentación del derecho internacional" empezó a llamar la atención en la práctica y a ser tratada de manera sistemática por la doctrina. Sin pretender indicar con exactitud el inicio de esta historia, podemos señalar los siguientes desarrollos como detonantes de la preocupación. Por un lado, el creciente número de campos regulados por el derecho internacional y la especificación cada vez mayor que han adquirido dichas ramas, sobre todo después de la guerra fría ${ }^{3}$ y a raíz de la globalización. Así observamos cómo el derecho internacional de los derechos humanos, que si bien se consolidó en buena medida durante el enfrentamiento de los grandes bloques, ha vivido un verdadero auge, particularmente jurisdiccional, en las últimas décadas. ${ }^{4}$ Que el derecho comercial internacional recibió una dimensión completamente distinta a partir de la puesta en marcha de la Organización Mundial de Comercio (OMC), en 1995, es indiscutible. ${ }^{5} \mathrm{Y}$

3 Si bien durante la guerra fría se lograron grandes avances en la historia de la codificación, en materias tales como las relaciones diplomáticas y consulares (convenciones de Viena de 1961 y 1963) o el derecho de tratados (Convención de Viena de 1969), por mencionar sólo algunas, también lo es que la oposición de los grandes bloques dificultó la construcción de consensos en otros rubros, como el derecho penal internacional. Al respecto, véase Nolte, Georg, "Sobre crisis y crecimiento del derecho internacional en sesenta años de Naciones Unidas", Anuario Mexicano de Derecho Internacional (AMDI), vol. VII, 2007, pp. 229 y ss.

4 Éste se ha manifestado, por un lado, en la creciente importancia que han adquirido los tribunales especializados, como lo evidencia la jurisprudencia de la Corte Europea de Derechos Humanos (CEDH), que ha alcanzado un estatus cuasi-constitucional en los ordenamientos jurídicos nacionales de los Estados miembros del Consejo de Europa, así como en la mayor trascendencia de la CIDH en los últimos lustros. Por otro lado, vemos cómo dicho auge ha propiciado un fuerte desarrollo en campos relacionados, como el derecho penal internacional y la incipiente jurisdicción universal, alterando así conceptos como la "soberanía" o las "inmunidades jurisdiccionales", que durante la guerra fría se mantuvieron herméticamente cerrados.

5 La especialización, trascendencia y alta eficacia del régimen de la OMC ha llevado a varios comentaristas a ver en él un orden cuasi-constitucional. Entre ellos es representativa la obra de Ernst-Ulrich Petersmann; véase, inter alia: "The WTO Constitution and Human Rights", Journal of International Economic Law (JIEL), vol. 3, 2000, pp. 19-25. Para un recuento completo del debate sobre la constitucionalización de la OMC, véase Cass, Deborah Z., The Constitutionalization of the World Trade Organization, Legitimacy, Democracy, and Community in the International Trading System, Oxford, 2005 . 
qué decir del derecho internacional del medio ambiente ${ }^{6}$ o del derecho penal internacional. ${ }^{7}$ Por otro lado, aunque evidentemente vinculado a lo anterior, está la proliferación de órganos internacionales, especialmente jurisdiccionales, como los tribunales penales especiales para la ex $\mathrm{Yu}-$ goslavia y Ruanda (TPIY y TPIR), de 1993 y 1994, la Corte Penal Internacional (CPI), de 1998, el Tribunal Internacional para el Derecho del Mar de 1996 (TIDM), los múltiples paneles internacionales en materia comercial, el Órgano de Apelaciones de la OMC, entre otros. Según datos publicados por el Project on International Courts and Tribunals, existen hoy en día más de veinte tribunales internacionales propiamente dichos, i. e., instituciones jurisdiccionales permanentes, a los cuales hay que sumarle, al menos, setenta órganos con facultades judiciales o cuasi-judiciales. ${ }^{8}$

6 El incremento sustancial de los problemas regulados por tratados medioambientales inició en la década de los setenta, tras la Declaración de Estocolmo de 1972. Desde entonces, el aumento ha sido constante, haciendo hoy del derecho internacional del medio ambiente una de las áreas del derecho internacional con el mayor número de tratados registrados. Cfr. Adede, Andronico O., International Environmental Law Digest, Instruments For International Responses to Problems of Environment and Development 1972-1992, Amsterdam, 1993, p. 13; así como Sands, Philippe, Principles of International Environmental Law, 2a. ed., Cambridge, 2003, pp. XXXV y ss., y 127. La variedad de temas que aborda esta rama va desde la atmósfera y el espacio ultraterrestre, los océanos, las reservas de agua y la diversidad biológica, hasta las sustancias y actividades peligrosas. En cuanto a la cada vez mayor especialización que ha experimentado, baste observar la complejidad institucional de varios de los tratados multilaterales de la era pos-Estocolmo. La Convención Marco de las Naciones Unidas sobre Cambio Climático de 1992 y su Protocolo de 1998 (Protocolo de Kyoto), así como el Convenio sobre la Diversidad Biológica de 1992 y su Protocolo de 2000 (Protocolo de Cartagena) son sólo algunos ejemplos de cómo dichos acuerdos multilaterales han establecido sistemas muy dinámicos de actualización normativa mediante las conferencias de las partes (COP, por sus siglas en inglés) y otros órganos específicos. En dicho sentido, se habla de "sistemas de tratados", lo cual denota un régimen multilateral altamente desarrollado y con un cierto grado de autonomía. Cfr. Gehring, Thomas, "Treaty-Making and Treaty Evolution", en Bondansky, Daniel et al. (eds.), The Oxford Handbook of International Environmental Law, Oxford, 2007, pp. 468-495.

7 A diferencia del derecho internacional del medio ambiente, cuya evolución en las últimas décadas obedece a una mayor concienciación mundial de los problemas medioambientales globales (cambio climático, riesgos transfronterizos y demás), el derecho penal internacional es uno de los típicos campos que fueron desbloqueados con el fin de la guerra fría.

8 La iniciativa fue creada en 1997 por el Center on International Cooperation (CIC) de la Universidad de Nueva York y la Foundation for International Environmental Law 
De lo anterior se desprende una primera aproximación conceptual al fenómeno. En términos generales, podemos decir que por "fragmentación del derecho internacional" se entiende su diversificación mediante la proliferación de instituciones y regímenes normativos que gozan de un alto grado de autonomía, así como los conflictos que surgen entre dichos regímenes e instituciones, y con el derecho internacional general y sus instituciones. De ahí que se suela hablar, por un lado, de "fragmentación institucional", $i$. e., la proliferación de instituciones, y, por el otro, de "fragmentación sustantiva", o sea la que atañe los conflictos normativos.

Un caso en particular refleja bien la inquietud general: el caso Tadic de 1999. Aquí, la Sala de Apelaciones del TPIY decidió cambiar el criterio adoptado por la Corte Internacional de Justicia (CIJ) en el caso Nicaragua, de 1986, sobre la atribución de responsabilidad del Estado por actos cometidos por grupos privados en conflictos armados. En este caso, la Corte había señalado el "control efectivo" como criterio de atribución, ${ }^{9}$ el cual no fue considerado suficientemente amplio para los fines humanitarios que persigue el TPIY, por lo que adoptó el criterio de "control general", ${ }^{10}$ indicando, además, que "en derecho internacional, cada tribunal es un sistema autónomo (salvo que se disponga lo contrario)". ${ }^{11}$

Inquietados por decisiones como Tadic $^{12}$ y los desarrollos a los que nos hemos referido, diversos jueces de la CIJ, particularmente Robert

and Development. Actualmente, se trata de un proyecto conjunto del CIC y del Centre for International Courts and Tribunals del University College de Londres, véase http:// www.pict-pcti.org/index.html.

9 Case Concerning Military and Paramilitary Activities in and against Nicaragua (Nicaragua vs. United States of America), Merits, ICJ, Reports of Judgments, Advisory Opinions and Orders, 1986, párr. 115. Los resúmenes de los fallos de la CIJ, así como el texto íntegro de algunas opiniones consultivas pueden consultarse ahora en español, directamente en la página web de la Corte: http://www.icj-cij.org/homepage/sp/.

10 The Prosecutor vs. Dusko Tadic, IT-94-1-A, del 15 de julio de 1999, párrs. $120 \mathrm{y}$ ss., en http://www.un.org/icty/tadic/appeal/judgement/tad-aj990715e.pdf.

11 The Prosecutor vs. Dusko Tadic, Decision on the Defence Motion for Interlocutory Appeal on Jurisdiction, del 2 de octubre de 1995, párr. 11

12 Otra decisión muy criticada por los jueces de La Haya, especialmente por Gilbert Guillaume, ha sido el fallo de la CEDH en el caso Loizidou vs. Turquía de 1995. En las objeciones preliminares, la Corte de Estrasburgo decidió apartarse del criterio tradicional seguido por la CIJ en torno a restricciones jurisdiccionales en materia de reservas territoriales, determinando que su jurisdicción no se limita al territorio nacional de los Estados parte de la Convención Europea para la Protección de los Derechos Humanos y las Libertades Fundamentales, sino que se hace extensiva a aquellas zonas sobre las cuales un 
Jennings, Stephen M. Schwebel y Gilbert Guillaume, empezaron a alertar sobre los peligros que, a su juicio, encierra el fenómeno, poniendo el énfasis, como era de esperarse, en la fragmentación institucional. ${ }^{13}$

Coincidiendo con la preocupación de los jueces de La Haya - y también en consecuencia a ésta - el tema "fragmentación del derecho internacional" fue introducido a largo plazo dentro del programa de trabajo de la Comisión de Derecho Internacional (CDI), en 2000. El estudio inicial estuvo a cargo de Gerhard Hafner. Como bien se desprende del título de dicho estudio, Riesgos resultantes de la fragmentación del derecho internacional, ${ }^{14}$ la preocupación predominante en ese momento estribaba en que el fenómeno "podría poner en peligro [la] estabilidad y coherencia del derecho internacional y su alcance general". ${ }^{15}$ Dos años después, la CDI comenzó a tratar el tema en su programa de trabajo, estableciendo un grupo de estudio, que encabezaría Bruno Simma. Una de las primeras medidas tomadas por ese grupo fue el cambio de título, pues se consideró que el original no era "totalmente adecuado, porque presentaba el fenó-

Estado parte ejerce control efectivo. Más allá, la CEDH justificó su disidencia de forma bastante provocadora, al equiparar a la CIJ con un "tribunal suelto", sin anclaje real en un tratado que establezca estándares sustantivos ("free-standing international tribunal wich has no link to a standard-setting treaty"). En tanto, ella se contempla a sí misma como el guardián constitucional del "orden público europeo" creado por la Convención de 1950. Cfr. CEDH, Loizidou vs. Turkey (Preliminary Objections), 23.03.1995, Publications of the European Court of Human Rights, series A, vol. 310, pp. 68 y 75. La crítica del juez Guillaume puede encontrarse en Speech by His Excellency Judge Gilbert Guillaume, President of the International Court of Justice, to the Sixth Committee of the General Assembly of the United Nations, del 27 de octubre de 2000, en http://www.icj-cij.org/ court/index. php? $p r=85 \& p t=3 \& p 1=1 \& p 2=3 \& p 3=1$.

13 Las inquietudes de los jueces Jennings, Schwebel y Guillaume se encuentran muy bien narradas en Koskenniemi, Martti y Leino, Päivi, "Fragmentation of International Law? Postmodern Anxieties", Leiden Journal of International Law (LJIL), vol. 15, 2002, pp. 554-556. Asimismo, pueden ser consultadas las intervenciones de los jueces Schwebel y Guillaume, en su calidad de presidentes de la Corte, ante el Pleno de la Asamblea General de Naciones Unidas y la Sexta Comisión, de 1999 y 2000, respectivamente, en http://www.icj-cij.org/court/index.php?p1=1\&p2=3\&p3=1. En el caso del juez Jennings, Koskenniemi y Leino remiten a un artículo de 1997, en el cual habla concretamente del peligro de que el derecho internacional se "fragmente". Cfr. Jennings, Robert, "The Role of the International Court of Justice", BYIL, vol. 58, 1997, p. 60.

$14 C f r$. A/55/10, Informe de la CDI, 52o. periodo de sesiones, anexo, pp. 294-310.

15 Ibidem, p. 295. 
meno... de una forma demasiado negativa". ${ }^{16} \mathrm{El}$ nuevo rótulo, Dificultades derivadas de la diversificación y expansión del derecho internacional, reflejaba mucho mejor la idea de que la fragmentación también tiene aspectos positivos y que no es correcto poner demasiado énfasis en los riesgos, pues si bien éstos existen, también es justo destacar las oportunidades que brinda el fenómeno ante el dinamismo de las nuevas realidades mundiales: la idea de la fragmentación como "signo de vitalidad del derecho internacional" 17 se había establecido. Y dicho enfoque prevalecería, como veremos más adelante, durante la gestión de Martti Koskenniemi, quien, a consecuencia de la elección de Simma a la CIJ, asumió la presidencia del grupo de estudio en 2003 y concluyó los trabajos de la CDI en 2006.

Como en la mayoría de los temas que aborda la CDI, su conclusión marca más bien un nuevo - y mejor documentado - punto de partida para el debate doctrinario y el desarrollo en la práctica. De tal suerte, la fragmentación del derecho internacional es hoy en día, y sin lugar a dudas, uno de los temas más importantes para los iusinternacionalistas. P. M. Dupuy, uno de los publicistas que inició el debate académico actual con su curso de la Academia de La Haya en $2000,{ }^{18}$ ha llegado a sostener que "la question de la fragmentation du droit international constitue par excellence le débat doctrinal à l'ère de la globalisation". ${ }^{19}$ Y no es para menos, pues hablar de fragmentación significa reflexionar sobre el estado actual del derecho internacional, $i$. e., sobre su condición como sistema jurídico, o bien, lo poco que hemos alcanzado al respecto a pesar de - o quizá debido a - la enorme juridificación de las relaciones internacionales y transnacionales en las últimas décadas. Y hablar de fragmentación es, sobre todo, preguntarse sobre la pertinencia de los funda-

16 A/57/10, Informe de la CDI, 54o. periodo de sesiones, párr. 500. En 2004, Simma comentaría al respecto: "Please note the Commission's move: while the term 'fragmentation' with its rather negative connotations was retained, the risks following from it were downgraded to difficulties now being regarded as arising from developments that are described in decidedly positive terms, namely diversification and expansion of international law". Simma, Bruno, "Fragmentation in positive light", Michigan Journal of International Law (MJIL), vol. 25, 2004, p. 847.

17 A/57/10, párr. 498.

18 Dupuy, Pierre-Marie, L'unité de l'ordre juridique international, Académie de Droit International de La Haye, Recueil des Cours, t. 297, 2002.

19 Dupuy, Pierre-Marie, "Un débat à l'ere de la globalisation: sur la fragmentation du droit international", European Journal of Legal Studies (EJLS), vol. 1, 2007. 
mentos dogmáticos sobre los que descansa el derecho internacional en estos tiempos de tremendos cambios e inestabilidad globales.

"Fragmentación" es un lema bajo el cual se acumulan una serie de llamados de atención sobre los riesgos para la coherencia y estabilidad del orden jurídico internacional. Así lo reflejan los pronunciamientos de los jueces de La Haya y, en un tono menos alarmista, el estudio inicial de la CDI. Lo interesante, y a veces difícil, es identificar dichos riesgos. La CDI, no hay duda, logró ubicar y describir algunos de ellos, pero esta labor no se ha agotado allí. No sólo debido a la naturaleza sumamente dinámica de los temas globales - la fragmentación es entendida desde diversas perspectivas como un epifenómeno de la globalización-, sino también porque algunos ven oportunidades en lugar de riesgos. Y esta es la segunda gran connotación que se le atribuye al lema, reflejada en las "eras Simma y Koskenniemi": "fragmentación" representa también el desarrollo normal y deseable del derecho internacional conforme a nuestros tiempos globalizados. Todo lo demás sería anacrónico y le restaría fuerza normativa; lo haría obsoleto ante la dinámica de la globalización.

En las siguientes páginas se intentará profundizar en este asunto; se verá en qué situaciones deberíamos hablar de riesgos y en cuáles, más bien, de oportunidades. Ello es, por supuesto, una cuestión de perspectiva. Bien dice el Informe de la CDI que "fragmentación y coherencia no son aspectos del mundo sino forman parte de la perspectiva del espectador". ${ }^{20}$ Por eso, tras presentar las visiones más representativas hasta ahora vertidas, se brindarán algunas reflexiones que puedan servir como incentivos para construir, en futuros debates e intercambios, un punto de vista desde México.

\section{PANORAMA DOCTRINARIO}

Siendo la fragmentación un lema muy atractivo en la actualidad, los significados que se le atribuyen dependen también de la agenda académica o incluso política de quienes lo usan. Por ello, un buen punto de partida para el presente análisis lo constituye el informe final de la $\mathrm{CDI},{ }^{21}$ ya que reúne buena parte de la doctrina internacional, aunque, como veremos, no sin tomar partido.

21 Cfr. A/CN.4/L.682. 


\section{La perspectiva optimista de la CDI}

El informe final de la CDI consolida los cinco subtemas que fueron analizados por el grupo de estudio a lo largo de cuatro años y que se limitan a analizar la denominada fragmentación sustantiva, i. e., los conflictos normativos resultantes de la diversificación y especialización de regímenes normativos, dejando fuera conflictos de competencia derivados de la proliferación de tribunales internacionales, ${ }^{22}$ aunque claro que ambos aspectos no son del todo separables. Los subtemas son: a) la relación entre ley especial y ley general, y el asunto de los regímenes autónomos o especiales; b) los conflictos entre normas sucesivas (artículo 30 de la Convención de Viena sobre el Derecho de Tratados de 1969 (CVDT)); c) la integración sistémica (artículo 31, 3 (c) de la CVDT); d) la modificación de tratados multilaterales entre algunas de las partes, $i$. $e$. los acuerdos inter se (artículo 41 de la CVDT), y e) la cuestión de la jerarquía normativa (ius cogens, normas erga omnes y artículo 103 de la Carta de las Naciones Unidas). ${ }^{23}$

Tal y como se le conoce, se trata de un verdadero estudio analítico, que versa expresamente sobre el "razonamiento jurídico". ${ }^{24}$ Por eso, se basa más en la doctrina internacional, así como en la teoría general del derecho, que en la práctica, aunque sí hay un muy buen anclaje en la jurisprudencia internacional. Probablemente se trate del trabajo más teórico que haya realizado la Comisión en sus sesenta años de existencia. Y ello no sólo se debe a la gran pericia de su coordinador, Martti Koskennie$\mathrm{mi},{ }^{25}$ sino a la propia naturaleza del tema, que lejos de confirmar la falsa impresión de que se trata de una preocupación más académica que práctica, muestra el grado evolutivo del derecho internacional como sistema jurídico propiamente, complejo y no primitivo. Los problemas que arroja el derecho internacional qua sistema son, forzosamente, problemas de

22 Ibidem, párr. 13.

23 Ibidem, índice.

24 Ibidem, párr. 20.

25 El reflejo de las cualidades teóricas de Koskenniemi sobre el Informe han sido bien descritas por Helmut Aust: "The reader of 'From Apology to Utopia' is immediately reminded of the search for the legal grammar, the langue of international law conditioning what can acceptably be said in international legal discourse and what not". Aust, Helmut P., "State Responsibility through the Prism of Diversity - the Articles on State Responsibility in the Light of the ILC Fragmentation Report", German Yearbook of International Law (GYIL), vol. 49, 2006, p. 174. 
teoría general del derecho: conflictos normativos, métodos de interpretación, relaciones jerárquicas, así como cuestiones de unidad e identidad de sistemas y subsistemas jurídicos. Por ello, no está fuera de lugar describir al presente Informe como un análisis sobre la relación de conceptos jurídicos fundamentales con algunos de los problemas más actuales del derecho internacional. ${ }^{26}$ Lejos de intentar un análisis detallado del largo Informe, veamos más bien qué entiende la CDI por "fragmentación", dónde ve sus problemas principales y qué soluciones propone.

En las conclusiones generales se le describe como un fenómeno derivado de la mundialización, que se manifiesta en la expansión e intensificación de redes globales de cooperación, con un alto grado de especialización técnica. Dichas redes desembocan en regímenes especiales de derecho internacional, basados en tratados multilaterales especializados y constituciones de organizaciones internacionales. ${ }^{27}$ El resultado es el conflicto, o, mejor dicho, las altas probabilidades de conflictos normativos entre dichos regímenes, así como entre ellos y el derecho internacional general. De ahí que tanto el propio Informe como las conclusiones anexas $^{28}$ se ocupen básicamente de conflictos normativos y sus posibles soluciones. Éstas se basan en la CVDT, específicamente en los artículos 30 y $31,3, c)$, o sea la norma conflictual lex posterior y el principio interpretativo de la integración sistémica. Asimismo, y en muy buena medida, en la regla lex specialis, que si bien no se encuentra plasmada en la CVDT, forma parte del derecho internacional, ya sea como costumbre o como principio general, y ha sido reconocida expresamente por la CIJ. ${ }^{29}$

26 Por supuesto que dichos conceptos jurídicos fundamentales forman parte del derecho internacional general; las normas conflictuales y los métodos de interpretación no sólo figuran en la CVDT, sino que, también, constituyen principios generales del derecho (artículo 38, $1 \mathrm{c}$ ) del Estatuto de la CIJ), donde también podemos ubicar la regla lex specialis (véase infra nota 29 y texto que le acompaña). No obstante, deseamos enfatizar que se trata de conceptos jurídicos fundamentales, más allá del derecho internacional, pues con ello se realza el carácter sistémico del mismo, $i$. e., su condición de orden jurídico. Así, la CDI menciona que lex specialis "funciona en el derecho internacional y en otras esferas del derecho entendidas como sistemas". Cfr. A/CN.4/L.682, párr. 119. Énfasis añadido.

27 Cfr. ibidem, párrs. 481-483.

28 Cfr. A/CN.4/L.702.

29 Sobre el particular, véase Simma, Bruno y Pulkowski, Dirk, "Of Planets and the Universe: Self-Contained Regimes in International Law”, European Journal of Interna- 
Cabe aclarar que no se pretende codificar la regla lex specialis, no sólo porque todo el Informe se aparta de dicho propósito, sino, concretamente, por las características de esta "técnica habitual del razonamiento jurídico", ${ }^{30}$ que se comporta de forma diferente, según el contexto, o sea, según la norma o el conjunto de normas generales que la definen como tal, pues, evidentemente, no hay norma especial si la hipótesis normativa que regula no se encuentra contemplada de una manera más general en otra norma. ${ }^{31}$ El objetivo del informe radica, más bien, en dilucidar su(s) significado(s) a fin de presentarla como una herramienta útil para la solución de conflictos en la práctica, $i$. e., en la determinación del derecho aplicable. Como técnica jurídica, la máxima lex specialis cobra una gran importancia en torno a los llamados "regímenes especiales", aspecto medular en el debate sobre la fragmentación.

Un "régimen especial" es un conjunto de normas que, de alguna manera u otra, se distingue del resto del material jurídico comprendido dentro de lo que reconocemos como "derecho internacional", tanto de su parte general como de otros regímenes particulares. Si ello es correcto, entonces, los regímenes especiales forman parte del derecho internacional, compuesto, por un lado, de normas generales sobre creación, modificación y derogación, así como de principios fundamentales de ese orden (su base axiomática), ${ }^{32} \mathrm{y}$, por el otro, de una serie de subconjuntos (subsistemas) de normas que regulan asuntos en particular. Nada a lo que los juristas no estemos acostumbrados de nuestros derechos domésticos; incluso pareciera que estamos hablando de derecho constitucional y derecho(s) administrativo(s). Visto así, los regímenes especiales no representan desafíos que no puedan ser superados mediante normas conflictuales, que nos indiquen, caso por caso, cuál es el derecho aplicable. Y así lo se-

tional Law (EJIL), vol. 17, núm. 3, 2006, pp. 486-487. Para un panorama de la recepción de la regla en la jurisprudencia internacional, véase A/CN.4/L.682, párrs. 68-84.

30 A/CN.4/L.682, párr. 119.

31 Ibidem, párr. 121.

32 Sin referirse expresamente a la "base axiomática", el informe hace referencia, por un lado, a las normas de creación, modificación y derogación, y, por el otro, a ciertos principios fundamentales que deben tomarse en cuenta a la hora de determinar la aplicación de la regla lex specialis y que, en ese sentido, determinan también creación y operación de los regímenes especiales. Aunque, al mismo tiempo, deja claro que aún es necesario ahondar en el significado del concepto "derecho internacional general" y definir con mayor claridad sus fuentes. Cfr. ibidem, párrs. 120 y 493, 3. 
ñala también la Comisión: "Una conclusión principal de este informe ha sido que la aparición de regímenes especiales... no ha socavado seriamente la seguridad jurídica, la previsibilidad del derecho y la igualdad de los sujetos jurídicos". ${ }^{33}$ El problema radica, más bien, en lo que denota el término "régimen autónomo" ("self-contained régime").

Dicho término fue introducido al discurso jurídico, curiosamente, por la CIJ en el caso sobre personal diplomático y consular. ${ }^{34}$ En reacción al argumento del gobierno iraní de considerar el conflicto relativo a la toma de rehenes estadounidenses en Teherán, principalmente diplomáticos, como parte de un problema más grande, que involucraba una serie de presuntos abusos (violación a la no intervención en asuntos internos, e. g.) por parte del personal de la Embajada de Estados Unidos acreditado en Irán, ${ }^{35}$ la Corte determinó que las reglas de derecho diplomático constituyen un "régimen autónomo", que establece contramedidas especiales y eficientes (declaración de persona non grata, por ejemplo) a disposición del Estado receptor por posibles abusos a cargo de los miembros de las misiones diplomáticas. ${ }^{36} \mathrm{Si}$ bien la Corte no quiso realmente separar el derecho diplomático del resto de la normatividad internacional, su argumento a favor de la aplicación de reglas especiales en materia de responsabilidad del Estado (contramedidas especiales como la declaración de persona non grata), contenidas en las convenciones de Viena de 1961 y 1963, abrió el camino al debate sobre la existencia de regímenes autónomos en el campo de la responsabilidad del Estado, i. e. de con-

33 Ibidem, párr. 492.

34 La expresión self-contained ya había sido utilizada por la Corte Permanente de Justicia en el caso Wimbledon de 1923, pero en torno a la aplicación de ciertas normas de un tratado frente al resto de ese mismo Tratado (el Tratado de Versalles). En el caso sobre personal diplomático y consular, la CIJ se refirió concretamente a una rama del derecho internacional, el derecho diplomático, como autónomo. Para la historia del concepto, véase, por todos, Simma, Bruno, "Self-Contained Regimes", Netherlands Yearbook of International Law (NYIL), vol. XVI, 1985, pp. 111-136.

35 Irán no se presentó a la Corte, pero sometió su posición mediante dos cartas. Cfr. Simma, Bruno, op. cit., nota anterior, p. 111.

36 Reports of Judgments, Advisory Opinions and Orders, Case concerning United States diplomatic and consular staff in Teheran (United States vs. Iran), Judgment of 24 May 1980, párr. 86. 
juntos especiales de reglas secundarias destinadas a excluir "la aplicación de las consecuencias jurídicas generales por hechos ilícitos". ${ }^{37}$

La Comisión identifica, al lado de la noción directamente relacionada con la responsabilidad del Estado, otros dos tipos de regímenes autónomos. El segundo tipo lo constituyen "los conjuntos interrelacionados de normas primarias y secundarias", ${ }^{38}$ es decir, de la unión de obligaciones especiales con reglas, también especiales, que regulan las consecuencias de la violación de las primeras. ${ }^{39} \mathrm{El}$ tercer tipo de regímenes autónomos está integrado, según la CDI, por aquellos que más allá de contener sus propias normas primarias y secundarias, reclaman "técnicas especiales de interpretación y administración". ${ }^{40}$ Realmente es difícil ver la diferencia conceptual entre el segundo y el tercer tipo que identifica la CDI, lo cual radica en el uso poco preciso del término "reglas secundarias" en derecho internacional. ${ }^{41}$ Parece tratarse de una distinción de grado, con la cual la comisión quiso enfantizar la existencia de regímenes cuyo mayor grado de autonomía es respaldado por un tratamiento diferenciado en la doctrina. ${ }^{42}$ Así, se habla de "derecho internacional de los derechos huma-

37 Simma, Bruno, op. cit., nota 34, p. 117. La traducción es nuestra. Sobre el problema de los regímenes autónomos en el campo de la responsabilidad internacional del Estado, véase, además, Simma, Bruno y Pulkowski, Dirk, op. cit., nota 29, así como Aust, Helmut P., op. cit., nota 25.

38 A/CN.4/L.682, párr. 128.

39 Si bien esta terminología está claramente basada en Hart, no queda del todo claro si al hablar de "reglas secundarias", la Comisión (y los iusinternacionalistas, en general) se refiere exclusivamente a las normas que regulan las consecuencias por violaciones a las obligaciones primarias, o bien, si la expresión adquiere toda su dimensión, comprendiendo reglas de reconocimiento, cambio (creación y derogación) y adjudicación (de facultamiento; dentro de las cuales se ubican las reglas sobre responsabilidad internacional del Estado). Cfr. Hart, H. L. A., The Concept of Law, 2a. ed., Oxford, 1997, pp. 94-97.

40 A/CN.4/L.682, párr. 129.

41 Aunque es justo mencionar que en las conclusiones anexas, la CDI parece limitar el segundo tipo a situaciones muy concretas, como las relaciones de los ríos transfronterizos o la regulación del uso de armas específicas. Cfr. A/CN.4/L.702, conclusión 12.

42 Corresponde a Ian Brownlie haber llamado la atención hace ya varios años respecto a la fragmentación doctrinaria o, como él la denomina, topic autonomy, misma que pondría en riesgo la unidad del derecho internacional al ser una especialización artificial, que ignora el lugar que ocupa la "rama" determinada dentro de la "matrix of rules of general international law". Brownlie, Ian, "Problems Concerning the Unitiy of International Law", Le Droit International a l'Heure de sa Codification, Études en l'Honneur de Roberto Ago, Milán, Università di Genova, Instituto di Diritto Internazionale e della Navigazione della Facultà di Giurisprudenza, 1987, t. I, p. 160. 
nos", "derecho comercial internacional" o inclusive "derecho internacional de las inversiones"; en fin, "ramas" a las que los comentaristas atribuyen principios propios y que los tribunales especializados, en su afán de defender la racionalidad de los tratados que los crearon, hacen suyos o desarrollan. ${ }^{43}$

Un régimen autónomo representa, entonces, la idea de un conjunto de normas e instituciones jurídicas sobre una materia específica de índole internacional o — cada vez en mayor medida - global, ${ }^{44}$ que se aísla del resto del derecho internacional. Se trata de "sistemas", toda vez que un "subsistema" implicaría, necesariamente, la adhesión al sistema, por más suelta que fuere. ${ }^{45}$ Pero ¿existe realmente algo así? Partiendo de la premisa de que por más autonomía que goce un cierto régimen, éste nunca se sale totalmente del sistema del derecho internacional, como lo ejemplifican las normas generales sobre la constitución (creación) del mismo, así como sobre su disolución parcial (sucesión), ${ }^{46} \mathrm{y}$, en última instancia pacta sunt servanda, ${ }^{47} i$. e., su propio fundamento de validez, la CDI niega esta posibilidad y deja muy claro que el término "régimen autónomo" conlleva sólo a confusiones, por lo que se debe hablar mejor de "regímenes especiales". ${ }^{48}$ Éstos surgen dentro del derecho internacional ge-

43 Cfr. A/CN.4/L.682, párrs. 129 y ss.

44 Por "global" entiendo aquí tanto el tratamiento a nivel internacional (interestatal) como transnacional (a nivel horizontal, i. e., sin pasar por los mecanismos de decisión centralizados de los Estados, pero afectando situaciones transfronterizas a escala mundial). Para un locus classicus sobre el derecho transnacional, véase Jessup, Philip C., Transnational Law, New Haven, 1950. Aunque cabe aclarar que Jessup comprende dentro del "derecho transnacional" la totalidad del derecho que regula los hechos y actividades que traspasan las fronteras nacionales, o sea más bien lo que aquí denominamos "derecho global".

45 Se habla frecuentemente de "subsistemas" con relación a los "regímenes autónomos" debido al (mal) uso que hizo del término Willem Riphagen, como relator especial del proyecto de artículos sobre responsabilidad del Estado. Riphagen identificó "subsistemas" con "regímenes", que denominó de varias formas, pero que tenían en común ser especiales y cerrados, y a los cuales atribuyó la característica de ser autónomos. Cabe aclarar que la terminología de Riphagen es muy confusa y la noción de "autonomía" es tratada en ocasiones de forma absoluta, en otras de manera relativa. Cfr. Simma, Bruno, op. cit., nota 29, pp. 113-117. Véase, también, A/CN.4/L.682, párrs. 139 y ss.

46 A/CN.4/L.682, párrs. 192 y 194.

47 Ibidem, párr. 176.

48 Ibidem, párrs. 152, 5) y 193. Si bien la comisión rechaza también el uso del término "subsistema", probablemente por las confusiones aparejadas al uso del mismo en épo- 
neral, no en un vacío legal. Los regímenes especiales operan como lex specialis, y lo que se dice sobre ésta vale igualmente para aquéllos: ${ }^{49}$ pueden "dejar a un lado" la aplicación del derecho general, pero no lo invalidan, y su libertad es sólo relativa, ya que sus fallas y lagunas, es decir, las limitaciones propias de su especificidad, hacen que "recurran supletoriamente" al derecho internacional general. ${ }^{50}$ Justo en ese sentido, la CIJ reconoció recientemente la existencia de un régimen especial en materia de protección de inversiones, señalando que si bien sólo en casos particulares y limitados, este régimen especial recurre al derecho general (de protección diplomática), una vez que sus normas y mecanismos de solución de controversias se han mostrado inapropiados ("where treaty régimes do not exist or have proved inoperative"). ${ }^{51}$

Es en este regreso forzoso al derecho general donde la interpretación sistémica, i. e., el principio normativo según el cual todo tratado debe ser interpretado a la luz de todas las normas relevantes de derecho internacional aplicables entre las partes (artículo 31, 3c de CVDT), adquiere gran importancia. ${ }^{52}$ Por supuesto que en dicho contexto las normas más relevantes son las que gozan de mayor jerarquía o que establecen una aplicación preferente. La CDI no lo niega y establece con toda claridad que "en caso de conflicto entre una de las normas jerárquicamente superiores... y otra norma de derecho internacional, esta última deberá interpretarse, en la medida de lo posible, de manera compatible con la prime-

cas anteriores de la CDI (véase la nota 45), este autor considera que dicho término bien podría aplicarse a los regímenes especiales, toda vez que denota con claridad su especificidad y, al mismo tiempo, su adhesión al sistema.

$49 C f r . \mathrm{A} / \mathrm{CN} .4 / \mathrm{L} .702$, conclusiones 11 y 14.

50 Aquí se alude a la tesis del contract out y fall-back de Joost Pauwelyn, en cuyos trabajos sobre conflictos normativos se basa fuertemente la Comisión. Cfr. Pauwelyn, Joost, Conflict of Norms in Public International Law - How WTO Law Relates to other Rules of International Law, Cambridge, 2003; Pauwelyn, Joost, "Bridging Fragmentation and Unity: International Law as a Universe of Inter-Connected Islands", MJIL, vol. 25, 2004; Pauwelyn, Joost, "Fragmentation of International Law", www.law.duke.edu/fac/ pauwelyn/pdf/fragmentation_of_international_law.pdf. Asimismo, los trabajos de Bruno Simma en torno a la relación de los regímenes especiales con las reglas generales sobre responsabilidad del Estado han influido al Informe, especialmente: Simma, Bruno, op. cit., nota 29. Para la recepción en el Informe $c f r$. A/CN.4/L.682, párrs. 172 y ss.

51 Case Concerning Ahmadou Sadio Diallo (Republic of Guinea vs. Democratic Republic of Congo), Preliminary Objections, 24 May 2007, párr. 88. Véase la nota 108.

52 El Informe describe la interpretación sistémica como una "llave maestra de la casa del derecho internacional". A/CN.4/L.682, párr. 420. 
ra. De no ser ello posible, prevalecerá la norma superior". ${ }^{53}$ A pesar de ello, y de dedicar una buena parte de su estudio al tema de la jerarquía normativa, ${ }^{54}$ la verdad es que la Comisión no vuelca demasiadas esperanzas en el ius cogens, las obligaciones erga omnes y el artículo 103 de la Carta para resolver los conflictos a los que nos hemos referido. Ello se debe, en principio, a los problemas que presentan dichas normas en cuanto a su determinación, ${ }^{55} \mathrm{o}$ sea, a su significado y alcance, y, por ende, a su aplicación concreta. Más allá, y éste es el motivo que pesa, la CDI rechaza contundentemente la existencia de jerarquías claras en el derecho internacional. ${ }^{56}$ De manera simbólica, denomina las relaciones sistémicas resultantes de la aplicación de dichas normas "relaciones de importancia”. Ius cogens, erga omnes y la prevalencia de las obligaciones de la Carta sí implican relaciones de superioridad e inferioridad, pero éstas se determinan en cada contexto y no de manera abstracta. Por ello, no hay que exagerar en cuanto a su potencial para resolver conflictos normativos verticalmente. De por sí, parece que la CDI pretende desmitificar "las máximas latinas", ${ }^{57}$ subrayando la mayor importancia práctica de otros principios normativos, así como de las cláusulas relativas al objeto y fin de los tratados. ${ }^{58}$

Lo anterior implica que las normas en comento no son de carácter constitucional, toda vez que no gozan, en abstracto y en general, de superioridad jerárquica frente al resto de las normas del orden jurídico. $\mathrm{Y}$ en efecto, el Informe de la CDI no adopta una postura a favor del llamado "constitucionalismo del derecho internacional", i. e., de aquella corriente del pensamiento jurídico que reconoce en dichas normas, en la Carta de Naciones Unidas en general y en los valores fundamentales de la comunidad internacional, una estructura constitucional (con jerarquías forma-

53 A/CN.4/L.702, conclusión 42).

54 Cfr. A/CN.4/L.682, párrs. 324-409.

55 Cabe mencionar que el Informe contribuye positivamente a la determinación de estas normas, tanto por lo que respecta a los alcances concretos del artículo 103 (extensión a las resoluciones obligatorias del Consejo de Seguridad, así como su aplicación frente a la costumbre internacional y su no aplicación vis à vis el ius cogens), como a la relación conceptual entre ius cogens y erga omnes. Cfr. idem.

$56 C f r$. A/CN.4/L.682, párrs. 407, 484, 485 y 493; asimismo, A/CN.4/L.702, conclusión 31 .

57 A/CN.4/L.682, párr. 407.

58 Idem. 
les y materiales) del orden jurídico internacional. ${ }^{59} \mathrm{La}$ CDI, en todo caso, ve en las normas mencionadas "un terreno fértil para reflexionar sobre la "constitucionalización", ${ }^{60}$ es decir, no desecha el tema, pero lo difiere a otros debates. De tal suerte, jerarquización y constitucionalismo no representan soluciones normativas satisfactorias para la CDI, ni un fundamento sólido para dotar (o reforzar) de coherencia al derecho internacional, sino que sólo "atenúan el grado en el que la fragmentación... aparece problemática". ${ }^{61}$ Ésa es la salida diplomática del Informe respecto a uno de los remedios con mayor potencial contra la fragmentación. Pero recordemos que la Comisión dejó de ver en este fenómeno un problema desde que Simma encabezó los trabajos respectivos. Con Koskenniemi, queda claro, esta perspectiva se mantuvo. De ahí que el gran remedio no parezca necesario: "la fragmentación... no plantea ningún verdadero peligro para la práctica jurídica... la aparición de nuevas 'ramas' del derecho, nuevos tipos de tratados o grupos de tratados es un rasgo de complejidad social de un mundo que se globaliza". ${ }^{62}$

En suma, podemos decir que la versión final de la CDI representa una perspectiva, según la cual, y como el título del informe lo indica, la diversificación y expansión del derecho internacional son evoluciones necesarias para garantizar su vitalidad, así como para responder mejor a las exigencias de un mundo globalizado y plural. ${ }^{63} \mathrm{Si}$ bien generan algunas dificultades de índole conflictual, las herramientas de las que disponen los juristas son suficientes para resolverlas. La contribución principal del Informe consiste, precisamente, en dilucidar las técnicas pertinentes. En tal sentido, se trata de una visión optimista - aunque no entusiastade la fragmentación, que vislumbra oportunidades, una vez superadas las dificultades.

Dentro de esta misma perspectiva podemos ubicar a la gran mayoría de los publicistas: desde Simma ${ }^{64}$ y Koskenniemi, ${ }^{65}$ en sus facetas acadé-

59 Véase el apartado B de esta sección.

60 A/CN.4/L.682, párr. 409.

61 Idem.

62 Ibidem, párr. 222.

63 A/CN.4/L.682, párr. 492. A/CN.4/L.702, párrs. 9 y 11.

64 Cfr. Simma, Bruno, op. cit., nota 16; Simma, Bruno y Pulkowski, Dirk, op. cit., nota 29.

65 El caso de Koskenniemi es más complejo. Sus críticas a los defensores de la unidad del orden, especialmente a los jueces de La Haya, son vehementes. Véase Koesken- 
micas, pasando por Pauwelyn ${ }^{66}$ y Paulus,${ }^{67}$ hasta Charney ${ }^{68}$ y Higgins, ${ }^{69}$ por mencionar sólo algunos. Si bien la mayoría de ellos no descarta del todo el constitucionalismo y reconoce sus contribuciones históricas al discurso jurídico internacional, considera que su rígidez no es apta para hacer frente a las dificultades contemporáneas, por lo que se inclinan hacia un pluralismo jurídico moderado, de alguna manera enmarcado en los parámetros del derecho internacional general; "entre la coherencia y el pluralismo", ${ }^{70}$ según las palabras de la Comisión. Pero ésta no es la única visión. La vieja perspectiva según la cual la fragmentación realmente plantea riesgos - y muy serios - no ha sido superada, ni se limita a algunos jueces de La Haya; se trata, en esencia, de la perspectiva de aquellos que continúan viendo en la constitucionalización del derecho internacional la solución al problema.

niemi, Martti y Leino, Päivi, op. cit., nota 13. No obstante y sin abandonar dichas críticas, en trabajos más recientes alerta con gran elocuencia sobre los riesgos inherentes a la alta especialización de los regímenes, así como sobre las deficiencias del pluralismo jurídico internacional. Cfr. Koskenniemi, Martti, Formalism, fragmentation, freedom. kantian themes in today's international law, conferencia presentada en Frankfort del Meno, Alemania, el 25 de noviembre de 2005, www.helsinki.fi/eci/publications/talks_pa pers_MK.htm; Koskenniemi, Martti, "The Fate of Public International Law: between Technique and Politics”, The Modern Law Review (MLR), vol. 70. 2007, pp. 1-30.

66 Véase nota 50.

$67 C f r$. Paulus, Andreas L., "From Territoriality to Functionality? Towards a Legal Methodology of Globalization“", en Dekker, I. F. y Werner, W. G. (eds.), Governance and International Legal Theory, Leiden-Boston, 2004, pp. 59-95; y más reciente Dekker, I. F. y Werner, W. G. (eds.), Zur zukunft der völkerrechtswissenschaft in deutschland: zwischen konstitutionalisierung und fragmentierung des völkerrechts, Zeitschrift für ausländisches öffentliches Recht und Völkerrecht (ZaöRV), 2007, vol. 67, pp. 695-719.

68 Cfr. Charney, Jonathan I., Is International Law Threatened by Multiple International Tribunals?, Académie de Droit International de La Haye, Recueil des Cours, t. 271, 1998; id., "The Impact on the International Legal System of the Growth of International Courts and Tribunals, Journal of International Law and Politics (JILP), vol. 31, 1999, pp. 697-708.

69 Cfr. Higgins, Rosalyn, "The ICJ, the ECJ, and the Integrity of International Law", The International and Comparative Law Quaterly (ICLQ), vol. 52, 2003, pp. 1-20; id., "A Babel of Judicial Voices? Ruminations from the Bench", ICLQ, vol. 55, 2006, pp. 791-804.

70 A/CN.4/L.682, párrs. 491 y ss. 


\section{La perspectiva del constitucionalismo}

Una manera de explicar la preocupación inherente a esta postura consiste en que a falta de claras jerarquías normativas existentes en el derecho internacional, la decisión de recurrir al sistema es contingente. El criterio a seguir es dictado por la racionalidad dominante de los regímenes en conflicto, no por una instancia superior que dicte la última razón. No sólo los partidarios abiertos del pluralismo jurídico internacional, ${ }^{71}$ sino también aquella gran mayoría que oscila entre un constitucionalismo flexible y un pluralismo moderado ponen muchas esperanzas en el diálogo entre los diferentes regímenes, especialmente entre sus tribunales. El problema para el constitucionalista radica en que por mejor que haya funcionado dicho diálogo en ciertos casos, la disposición al mismo siempre será un asunto de cortesía por parte de los portavoces del régimen particular. ${ }^{72}$ Ello pone en riesgo la certeza jurídica y la predictabilidad objetiva, haciendo del derecho internacional un (des)orden basado en las diferentes orientaciones políticas y, debido a la especialización técnica de los regímenes, cada vez más en las orientaciones cognitivas, mas no en la validez formal: la esfera objetiva del derecho queda, en el mejor de los casos, relegada a un segundo plano.

Ahora bien, ¿a quién afecta esta situación? Afecta, sin duda, a la CIJ en sus pretensiones de máximo tribunal internacional. Pero ¿es ello nocivo para los principales sujetos del derecho internacional o incluso para la comunidad en su conjunto? Sin duda, ello depende de la perspectiva, pero es importante seguir escuchando los siguientes argumentos. La proliferación de tribunales con competencias que en ocasiones se traslapan, conlleva a la búsqueda del foro más favorable (forum shopping), una actividad que privilegia a quienes tienen los mayores recursos para escoger el foro y todo lo que ello implica. Asimismo, se sostiene que la forma garantiza cierto grado de igualdad, por lo que la coherencia del sistema es también un objetivo deseable para los Estados menos poderosos. Y a la comunidad internacional le afectan seriamente las amenazas al sistema

71 Véase el apartado C de esta sección.

72 En el caso MOX Plant, por ejemplo, el Tribunal de Arbitraje decidió diferir el caso, por "dictados de respeto y compromiso mutuos" según su presidente, hasta que las implicaciones de otros regímenes (el comunitario europeo) fueran aclaradas. En tanto, el TJCE se concentró en las violaciones a su normatividad, sin importarle demasiado las cuestiones ajenas a su sistema. Cfr. Koskenniemi, Martti, op. cit., nota 5, p. 7. 
jurídico qua sistema, pues los mínimos denominadores comunes que la sostienen se han logrado en virtud de la confianza que generan la certeza jurídica y la predictabilidad objetiva. Se trata, finalmente, de una comunidad de derecho.

Desde esta perspectiva, la solución radica en el fortalecimiento de la jerarquía normativa del derecho internacional: el énfasis ya no está en reglas conflictuales, sino en ius cogens, obligaciones erga omnes y el artículo 103 de la Carta, así como en los valores fundamentales de la comunidad internacional en su conjunto. Asimismo, la CIJ y, en términos generales, las Naciones Unidas desempeñan un rol principal. Simplemente piénsese en la propuesta original de Georges Abi-Saab de enviar las controversias que impliquen la aplicación de derecho internacional general frente a regímenes especiales, en algo así como la cuestión prejudicial del TJCE, a la CIJ. ${ }^{73}$ Por su parte, P. M. Dupuy también aboga por un fortalecimiento de la Corte a favor de la unidad del orden jurídico internacional. ${ }^{74} \mathrm{Si}$ bien Abi-Saab y Dupuy no son comúnmente considerados integrantes de la escuela del constitucionalismo, ${ }^{75}$ las tesis esbozadas

73 Cfr. Abi-Saab, Georges, "Fragmentation or Unification: some Concluding Remarks", JILP, vol. 31, 1999, p. 928. La propuesta fue posteriormente retomada por los jueces Schwebel y Guillaume, véase nota 13.

74 Véase, particularmente, Dupuy, P. M., "The Danger of Fragmentation or Unification of the International Legal System and the International Court of Justice", JILP, vol. 31, 1999, pp. 801-807.

75 El "constitucionalismo del derecho internacional" es una escuela básicamente alemana, que tiene sus orígenes en Alfred Verdross. Dentro de sus representantes más importantes en la actualidad podemos mencionar a los profesores Christian Tomuschat, Bardo Fassbender y Armin von Bogdandy. Una versión novedosa dentro de dicha escuela la constituye aquélla representada por Stefan Kadelbach y Thomas Kleinlein, que se centra en la "constitucionalización" en el derecho internacional, prestando especial atención a ciertos principios normativos que cumplen una función constitucional en el derecho de gentes. Desde una perspectiva filosófica, Jürgen Habermas también ha suscrito algunas de las tesis más importantes del constitucionalismo. Véase Verdross, Alfred, Die einheit des rechtlichen weltbildes auf der grundlage der völkerrechtsverfassung, Tubinga, 1923; id., Die verfassung der völkerrechtsgemeinschaft, Viena, 1926; id., y Simma, Bruno, Universelles völkerrecht, theorie und praxis, Berlín, 1976; Tomuschat, Christian, Obligations Arising for States without or Against their Will, Académie de Droit International de La Haye, Recueil des Cours, t. 241, 1993; id., International Law: Ensuring the Survival of Mankind on the Eve of a New Century, Académie de Droit International de La Haye, Recueil des Cours, t. 281, 1999; Fassbender, Bardo, "The United Nations Charter as Constitution of the International Community", Columbia Journal of Transnational Law (CJTL), vol. 36, 1997; Verdross, Alfred, Grund und grenzen der konstitutionellen idee im 
por ellos en el marco del debate sobre la fragmentación se basan, sin duda, en dicha corriente. En el caso de Dupuy, es incluso plausible ubicarlo dentro de la misma, aunque, por supuesto, con sus especificidades.

Según Dupuy, el orden jurídico internacional se encuentra unido mediante reglas formales de reconocimiento, cambio y adjudicación (la responsabilidad del Estado ocupa aquí un papel central), por un lado, y normas que gozan de una mayor jerarquía debido a su contenido significativo (ius cogens). Mientras las primeras nos permiten identificar (reconocer) los medios de creación y aplicación del derecho internacional, las segundas nos indican los contenidos mínimos del orden, es decir, su base axiomática. ${ }^{76}$ La teoría de las dos unidades de Dupuy se basa en su primera parte en Hart, mientras que la segunda está claramente anclada en el constitucionalismo alemán; simplemente, véase la definición de "constitución de la comunidad internacional" de Christian Tomuschat: "a legal framework determining certain common values as the guiding principles States are bound to observe and respect". ${ }^{77}$

No es de asombrarse que en este contexto las miradas estén parcialmente puestas hacia la Unión Europea, toda vez que aquí es donde la constitucionalización de las relaciones internacionales ha obtenido sus mayores logros, a pesar del aparente fracaso de la Constitución europea. ${ }^{78}$

Ahora bien, habíamos mencionado que los partidarios de la primera perspectiva oscilan frecuentemente entre constitucionalismo y pluralismo, que, como bien argumenta Koskenniemi, son las dos respuestas prin-

völkerrecht, en Depenheuer, Otto et al., Staat im wort, festschrift für Josef Isensee, Heidelberg, 2007; von Bogdandy, Armin, "Constitutionalism in International Law: Comment on a Proposal from Germany", Harvard International Law Journal (HILJ), vol. 47, 2006; Kadelbach, Stefan y Kleinlein, Thomas, "International Law - a Constitution for Mankind? An Attempt at a re-appraisal with an Analysis of Constitutional Principles", GYIL, vol. 50, 2007; Habermas, Jürgen, Hat die konstitutionalisierung des völkerrechts noch eine chance?, en Verdross, Alfred, Der gespaltene westen, Francfort del Meno, 2004.

76 Cfr. Dupuy, P. M., op. cit., notas 18 y 19.

77 Citado por Fassbender, Bardo, op. cit., nota 75, p. 82.

78 Cfr. Rodiles Bretón, Alejandro, Hacia una Constitución europea: perspectivas jurídico-politicas, México, 2007. 
cipales a la fragmentación. ${ }^{79}$ Es momento de ver, entonces, en qué consiste el pluralismo, aunque sea a grandes rasgos.

\section{Las perspectivas del derecho global}

Actualmente, la versión más elaborada del pluralismo jurídico internacional ha sido desarrollada por los alemanes Andreas Fischer-Lescano y Gunther Teubner, y está directamente basada en la teoría social de sistemas de Niklas Luhman. ${ }^{80}$ Según su tesis central, un orden jurídico internacional jerarquizado simplemente ya no es viable, pues la fragmentación del derecho internacional no es más que un reflejo de la "diferenciación funcional" de la sociedad global, proceso que el derecho, como subsistema social, no puede frenar. Esta sociedad global ya no cuenta con un centro, ni es internacional propiamente dicha. Más bien se trata de un conglomerado policéntrico de regímenes autónomos — ahora sí, en todo el sentido de la palabra - que se mueven a nivel transnacional, impulsados por su inherente maximización racional. Los Estados y las propias Naciones Unidas, dénse cuenta o no, participan en diversos regímenes al mismo tiempo, por lo que las mismas demandas de coherencia y unidad de un sistema universal, de ese "derecho de gentes universal" del que hablaba Alfred Verdross, ya resultan, en el mejor de los casos, inofensivas.

Ante ello, el derecho global plural —más que internacional, pues abarca tanto mecanismos tradicionales interestatales como horizontales transnacionales - debe intentar crear las condiciones necesarias de coordinación entre los diferentes regímenes. Para el derecho general no queda ya mucho espacio, en vez de remitir al ius cogens o las obligaciones erga omnes, o bien, poner demasiadas esperanzas en las reglas conflictuales y la integración sistémica, es necesario facilitar la creación de un nuevo derecho non dispositivum, que surja de las propias racionalidades de los múltiples regímenes y del diálogo entre ellos: un nuevo ordre public global.

79 Cfr. Koskenniemi, Martti, op. cit., nota 65.

80 Me baso en las próximas líneas de Fischer-Lescano, Andreas y Teubner, Gunther, Regime-kollisionen, zur fragmentierung des globalen rechts, Francfort del Meno, 2006. Las tesis principales de este libro también pueden ser consultadas en inglés, véase tambien Fischer-Lescano, Andreas y Teubner, Gunther, "Regime-collisions: the Vain Search for Legal Unity in the Fragmentation of Global Law", MJIL, vol. 25, 2004, pp. 999-1045. 
Dentro del incipiente pluralismo jurídico internacional ${ }^{81}$ podemos ubicar varias versiones. Según Fischer-Lescano y Teubner, como vimos, el derecho de regímenes, o sea, una nueva especie de derecho conflictual a escala global, representa una modesta, pero la única manera de enfrentar la inevitable fragmentación del derecho global. Otros apuestan por un diálogo entre cortes nacionales e internacionales, basado en un reconocimiento recíproco de las tres esferas básicas de representación y responsabilidad, $i$. e. la nacional, la internacional y la cosmopolita, en el sentido de tomar en cuenta en cada decisión las tres circunscripciones (constituencies) que reclaman legítimamente control sobre la regulación de una determinada materia. ${ }^{82}$ Por su parte, algunas tendencias que tienen sus bases, más bien, en el realismo de las relaciones internacionales (RI), se mezclan con algunos de los argumentos centrales del pluralismo. En estos últimos casos, la noción de lo jurídico es extendida al grado de fusionar el derecho internacional con teorías de RI, en donde lo aplicable ya no es necesariamente el derecho, sea especial o general, sino, y en muy buena medida, las pautas que dicta la gobernanza global. ${ }^{83}$

Todas ellas reconocen el sacrificio que suponen sus tesis para la certeza jurídica, pero tal aspiración es de por sí imposible ante la sociedad global o, en el mejor de los casos, se piensa que la formalidad y rigidez legales restarían expresión a la pluralidad de los diversos regímenes transnacionales.

81 Es importante recordar que el pluralismo jurídico tiene una trayectoria mucho más larga dentro los derechos domésticos de países con poblaciones indígenas. Diversos países latinoamericanos, entre ellos México, son un buen ejemplo. Por eso pensamos que la doctrina internacional debería orientar más sus miradas hacia los pluralistas latinoamericanos. Un diálogo incipiente en dicho sentido puede encontrarse en: Correas, Óscar (coord.), Pluralismo jurídico, otros horizontes, México, 2007. En general, la obra de Correas, reflejada en buena parte en la revista Crítica Jurídica, es ilustrativa al respecto.

82 Cfr. Krisch, Nico, "The Pluralism of Global Administrative Law", EJIL, vol. 17, 2006, pp. 247-278.

83 Los trabajos más representativos al respecto son los de Anne-Marie Slaughter. Cfr., entre otros, Slaughter, Anne-Marie et al., "International Law and International Relations. Theory: a New Generation of Interdisciplinary Scholarship", American Journal of International Law, vol. 92, 1998, pp. 367-397. Véase también el número especial sobre Legalization and World Politics de la International Organization (IO), vol. 54, núm. 3, 2000. Para una versión más anclada en el pluralismo jurídico, pero que también abre el concepto del derecho ampliamente: $c f r$. Berman, Paul S., "From International Law to Law and Globalization”, CJTL, vol. 43, 2005, pp. 485-556. 
Hasta este punto hemos repasado las perspectivas más comunes generadas en torno a la fragmentación, pero existen otras que, si bien no han tenido la resonancia de las anteriores, revisten una importancia especial para una eventual perspectiva mexicana.

\section{4. ¿Nostalgias de Occidente?}

Tanto el informe de la CDI como el pluralismo parten de la premisa de que la fragmentación es un epifenómeno de la globalización, y el constitucionalismo no lo disputa. En efecto, contemplar la fragmentación como la manifestación jurídica de la intensificación a nivel global de los vínculos comerciales, financieros, socioculturales, comunicativos y demás parece un lugar común. Sin embargo, es importante cuestionarse si el derecho internacional realmente se encontraba en un estado de coherencia y unidad antes de la globalización.

\section{A. ¿Pasados inexistentes?}

Para muchos, el derecho internacional siempre se ha encontrado en una situación precaria, que difícilmente se ajusta a las exigencias del concepto de "orden jurídico". La idea del derecho internacional como una simple colección de normas de dudosa naturaleza jurídica se encuentra arraigada dentro de la filosofía del derecho — como es bien sabidoen la jurisprudencia analítica anglosajona.

Para el padre de esta escuela, John Austin, no se trata de "derecho propiamente dicho", sino de "moral positiva", la cual consiste en normas morales a las que la opinión general les atribuye carácter jurídico por mera analogía con el derecho propiamente dicho. En realidad, se trata de opiniones o sentimientos respecto a una conducta humana, que carecen del respaldo de la amenaza del uso de la fuerza en caso de incumplimiento (no son mandatos, i. e., commands), y - lo cual es muy importante y comúnmente soslayado - que no son adoptados (puestos) por el soberano, sea expresamente o por aquiescencia, es decir, no son derecho positivo (ius positum est). De ahí que el derecho internacional, en los ojos de Austin, no vaya más allá de, por ejemplo, las reglas de cortesía. Específicamente nos dice:

There are laws which regard the conduct of sovereigns or supreme governments in their various relations to one another. And laws or rules of 
this species, which are imposed upon nations or sovereigns by opinions current amongst nations, are usually styled the law of nations or international law. Now a law set or imposed by general opinion is a law improperly so called. It is styled a law or rule by an analogical extension of the term. ${ }^{84}$

Exactamente un siglo después, Hart diría que el derecho internacional se encuentra en un "estado de transición" de un sistema normativo primitivo (una colección de reglas primarias, i. e. obligaciones sustantivas), hacia un sistema jurídico propiamente, o bien, la una unión de reglas primarias y secundarias (reglas adjetivas de adjudicación, cambio y reconocimiento). Hart no cuestiona que el derecho internacional cuente con ciertas reglas de adjudicación y cambio, por ello el comentario frecuente de que Hart califica al derecho internacional como un orden primitivo no es acertado. Lo que cuestiona seriamente es la existencia de una regla básica de reconocimiento que otorgue unidad a la colección de normas internacionales, es decir, que lo transforme en un sistema jurídico. La norma fundamental del derecho internacional según Kelsen, i. e., la norma que instituye la costumbre internacional como acto creador del derecho, no dice, según Hart, otra cosa más que los Estados deben comportarse como habitualmente se comportan.$^{85} \mathrm{Y}$, como si hubiese anticipado las ansiedades inherentes al debate contemporáneo, destaca que las carencias del derecho internacional qua sistema no deberían ocultar el hecho social de que sus normas funcionan bien entre los Estados: "These simple truths about different forms of social structure can, however, easily be obscured by the obstinate search for unity and system". ${ }^{86}$

Fuera de la jurisprudencia analítica, los cuestionamientos también se han hecho escuchar. Incluso el más prominente defensor de la existencia del orden jurídico internacional, Hans Kelsen, admitió, prácticamente al mismo tiempo que Hart (la segunda edición de la Teoría pura del derecho fue publicada en 1960, un año antes que el Concepto del derecho), que si bien se trata de un orden jurídico, éste es, a comparación del derecho nacional, todavía primitivo, pues se encuentra en un estado altamen-

84 Austin, John, The Province of Jurisprudence Determined, Londres, 1861, p. 127; disponible en: http://books.google.com.

85 Cfr. Hart, H. L. A., op. cit., nota 39, pp. 236-237.

86 Ibidem, pp. 235 y 236. 
te descentralizado. ${ }^{87}$ Todo ello refleja bien, y sin necesidad de recordar los cuestionamientos desde la teoría de las RI a partir de Hans Morgenthau, cómo las dudas sobre la existencia del "orden jurídico" internacional han acompañado a nuestra disciplina la mayor parte de su trayectoria.

Bajo esta lupa ya no sería tan evidente identificar la fragmentación como una manifestación propia de nuestros tiempos globalizados. Tendríamos, entonces, que suponer que el fenómeno es intrínseco al derecho internacional. Según este razonamiento, la preocupación contemporánea obedecería básicamente a lo siguiente. ${ }^{88}$

La política internacional durante la guerra fría permitía justificar el desorden. Por un lado, el hermetismo tradicional de los Estados soberanos, y la parálisis parcial provocada por el enfrentamiento de los grandes bloques, por el otro, brindaban muy buenas excusas para la falta de desarrollo del derecho internacional, no sólo hacia nuevos campos temáticos, sino también en cuanto a la coherencia general del sistema. ${ }^{89}$ El colapso de ese "desorden ordenado" habría despertado una firme creencia en una nueva unidad internacional: "Sometime in the 1990's this began to seem a rather well-ordered and firmly structured world... the tranquil globalisation of the Western State form, the single rationality of public diplomacy here, the empire of Western economics and civil society there". ${ }^{90}$ Pero esta esperanza habría sido sólo un espejismo, reflejado en el lema del "nuevo orden mundial", que antes de cobrar forma sería quebrantado por la dinámica de la globalización, que empezó a apuntar hacia direc-

87 Cfr. Kelsen, Hans, Reine rechtslehre, 2a. ed., Viena, 1992, pp. 323-324. En efecto, fue Kelsen y no Hart, como le es a menudo y erróneamente atribuido, quien describió al derecho internacional como un orden jurídico primitivo. La distinción es importante, pues el uso del adjetivo "primitivo" conlleva a consecuencias significativas muy distintas en cada una de las teorías.

88 Esta línea argumentativa se encuentra desarrollada en Koskenniemi, Martti y Leino, Päivi, op. cit., nota 13, p. 559.

89 Una idea recurrente durante la guerra fría, que a la fecha no ha sido del todo erradicada, consistía en que mientras ciertos aspectos de las relaciones internacionales eran eficazmente regulados por el derecho, como las relaciones diplomáticas y consulares, en la mayoría de los ámbitos restantes, y en algunos de gran trascendencia como la igualdad jurídica de los Estados y, hasta cierto punto, la proscripción del uso de la fuerza, éste sólo existía en el papel. Curiosamente, una de las manifestaciones más evidentes del mundo unipolar, la guerra contra Iraq de 2003, revivió justo esa imagen.

90 Koskenniemi, Martti, Global Legal Pluralism: Multiple Regimes and Multiple Modes of Thought, conferencia impartida en la Universidad de Harvard, Estados Unidos, el 5 de marzo de 2005,www.helsinki.fi/eci/publications/talks_papers_MK.htm. 
ciones muy diversas, saliéndose de control: "but liberalism and globalisation did not bring about coherence, to the contrary. The structure provided by the East-West confrontation was replaced by a kaleidoscopic reality in which competing actors struggled to create competing normative systems". ${ }^{91}$ Llevando este argumento al final, el discurso de la fragmentación sería, en efecto, una "ansiedad posmoderna", 92 despertada por la añoranza de un pasado que nunca fue.

B. ¿Un orden? Quizá, pero ¿de quién?

Más allá de si la globalización es la verdadera causa de la fragmentación o no, la interpretación que antecede es importante, pues alerta sobre la posibilidad de que el debate que nos ocupa corresponda a los miedos de una clase establecida de perder el control sobre los mecanismos de toma de decisión tradicionales. Justamente de esta idea parte la perspectiva sobre la fragmentación de la escuela de los Critical Third World Approaches to International Law (TWAIL), al menos en la versión de Obiora Okafor. ${ }^{93}$

Para dicha corriente, los esfuerzos por la inclusión del hoy llamado tercer mundo bajo el estandarte de la unión del orden jurídico internacional han sido, desde los tiempos de la conquista española, pasos dirigidos a la subordinación de ese mundo marginal al orden preestablecido. ${ }^{94} \mathrm{El}$ debate contemporáneo sobre la fragmentación se enmarca en esta línea histórica, al reflejar la renuencia a expandir el derecho internacional hacia nuevos campos que favorezcan a los menos poderosos, como la responsabilidad internacional de las empresas transnacionales o la completa reestructuración jurídica de las deudas de los países menos desarrollados, más allá de simples y esporádicos alivios de deuda. ${ }^{95}$

Sobre todo, lo que haría falta, según Okafor, sería la diversificación de la óptica del derecho internacional, ${ }^{96}$ es decir, del enfoque conceptual

91 Koskenniemi, Martti y Leino, Päivi, op. cit., nota 13, p. 559.

92 Idem.

93 Cfr. Okafor, Obiora, Viewing international legal fragmentation from a third world plane: A TWAIL Perspective, Proceedings of the 34rd Annual Conference of the Canadian Council on International Law, Ottawa, 2006, pp. 115-132.

94 Ibidem, p. 130.

95 Ibidem, pp. 122-125.

96 Ibidem, p. 122. 
e ideológico mediante el cual construye identidades y narra situaciones. El enfoque unidimensional existente es ejemplificado por Okafor con la construcción del "terrorista", que reproduce e intensifica los temores de Occidente al mismo tiempo que opaca preocupaciones de otras naciones en torno a las manifestaciones del terrorismo de Estado. ${ }^{97}$ Que bajo dicha perspectiva la unidad del sistema no parezca un objetivo deseable, es incluso reconocido por la CDI: "Cuando un sistema jurídico se considera injusto o impracticable en algunos aspectos no aporta ningún valor el hecho de que lo haga de forma coherente" ${ }^{98}$

No obstante, resulta también cuestionable si los cambios en el sistema, que es por lo que Okafor finalmente aboga, son incompatibles con las aspiraciones de unidad y coherencia formales. Cubrir temas hasta ahora no explorados y aproximarse a ciertas situaciones desde puntos de vista tradicionalmente sofocados no significa, necesariamente, fragmentar, ni es la preocupación por la ausencia de un orden previsible y objetivo, forzosamente, una ansiedad por mantener viejas injusticias. La demanda de modificar determinados contenidos significativos es perfectamente compatible con la necesidad de mantener y reforzar la base estructural. De hecho, la fragmentación puede ser vista como un serio obstáculo para perseguir los fines legítimos de los Estados menos poderosos, así como para la democratización de los procedimientos formales de toma de decisión.

\section{Fragmentación como estrategia de poder}

Eyal Benvenisti y George Downs ${ }^{99}$ argumentan convincentemente que a fin de evitar o mitigar la coordinación de Estados menos poderosos en foros internacionales, los Estados más poderosos, en particular - pero no exclusivamente - Estados Unidos, han desarrollado y empleado exitosamente diversas tácticas de fragmentación. De tal suerte, el fenómeno que nos ocupa es visto como una estrategia de poder destinada a conservar el control internacional.

97 Ibidem, pp. 126 y 127.

98 A/CN.4/L.682, párr. 491.

99 Las siguientes líneas están basadas en Benvenisti, Eyal y Downs, George W., "The Empire's New Clothes: Political Economy and the Fragmentation of International Law", Stanford Law Review (SLR), vol. 60, 2007, pp. 595-631. 
Son cuatro las tácticas específicas que describen los autores; aquí nos concentraremos en las dos que consideramos más relevantes para la construcción de nuestra propia perspectiva. La primera se refiere a la práctica de negociar y celebrar una serie de tratados específicos y limitados, preferentemente bilaterales, en lugar de la negociación en conferencias diplomáticas y foros instituidos de tratados más amplios, integrales y multilaterales. La segunda puede describirse, grosso modo, como una tendencia creciente de apartarse de las instituciones. ${ }^{100}$ Ciertamente, esta tendencia ha estado en comento desde hace ya algunos años, ${ }^{101}$ pero corresponde a Benvenisti y Downs haberla ubicado dentro del fenómeno de la fragmentación, contribuyendo así a una mejor comprensión de los fines que se persiguen mediante dicha táctica.

La primera táctica se manifiesta en lo que dichos autores denominan "bilateralismo en serie" (serial bilateralism), ${ }^{102}$ una tendencia conocida y que había sido previamente identificada como estrategia de poder por Nico Krisch. ${ }^{103}$ El bilateralismo en serie se puede constatar mediante la enorme cantidad de acuerdos para la promoción y protección recíproca de inversiones (APPRI) registrados, ${ }^{104} \mathrm{o}$ bien, en virtud del sinnúmero de convenios para evitar la doble tributación. Un caso menos comentado es el de los acuerdos que se celebran en el marco de la Proliferation Security Initiative (PSI) en materia de persecución, detención e inspección de

100 Ibidem, pp. 610-612 y 614-619, respectivamente.

101 Así lo muestran los trabajos de Anne-Marie Slaughter respecto a las redes intergubernamentales como forma cada vez más frecuente e importante de cooperación internacional. Cfr. Slaughter, Anne-Marie, A New World Order, Princeton, 2004. Por su parte, en su excelente análisis sobre la relación de los poderes hegemónicos de los diferentes periodos históricos con el derecho internacional, Nico Krisch se refiere a dicha tendencia como estrategia de poder, aunque nos alerta que la misma no es absoluta, ya que en ciertas constelaciones, especialmente cuando el status quo es favorable al Estado dominante, éste tiende a favorecer las instituciones como una forma de estabilización del poder. Cfr. Krisch, Nico, "International Law in Times of Hegemony: Unequal Power and the Shaping of the International Legal Order", EJIL, vol. 16, núm. 3, 2005, pp. 375 y ss. El propio Benvenisti es uno de los observadores más perspicaces de dicha tendencia en la actualidad. Véase, además del artículo en comento, Benvenisti, Eyal, Substituting International Law, Panel on the Move from Institutions?, American Society of International Law (ASIL), Proceedings, 100, 2006, pp. 289-294. Véase también dicho panel de la ASIL en general.

102 Benvenisti, Eyal y Downs, George W., op. cit., nota 99, pp. 610 y 611.

103 Cfr. Krisch, Nico, op. cit., nota 101, pp. 388-390.

104 Cfr. Benvenisti, Eyal y Downs, George W., op. cit., nota 99, pp. 610 y 611. 
buques en alta mar con fines de combatir el tráfico de armas de destrucción masiva (ADM). Aunque el número de éstos es mucho menor que el de aquéllos, ${ }^{105}$ dicha evolución encuadra perfectamente en la noción del bilateralismo en serie. Los efectos negativos de esta estrategia de fragmentación para Estados menos poderosos son evidentes. Las negociaciones multilaterales permiten la coordinación entre los mismos a fin de contrarrestar la imposición de los intereses de los más poderosos. Las ventajas de las negociaciones bilaterales para éstos, en cambio, son obvias. Como destacan Benvenisti y Downs, la fallida negociación del Acuerdo Multilateral sobre Inversiones (AMI) en el marco de la OCDE a finales de los noventa, que dio precisamente lugar a la proliferación de los famosos APPRI, demuestra con claridad por qué Estados poderosos optan por la vía bilateral cuando la multilateral se les complica. ${ }^{106}$ En una entrevista reciente, el secretario del Comercio de Estados Unidos, Carlos Gutiérrez, dijo que debido a las dificultades en la ronda de negociaciones de Doha, Estados Unidos ha optado por "otro camino, que se ha mostrado más exitoso. Concluimos acuerdos bilaterales". ${ }^{107}$

Más allá, el bilateralismo en serie confiere la posibilidad de crear costumbre internacional, como es ejemplificado, una vez más, con los alrededor de 2200 APPRI en vigor. ${ }^{108}$ Cabe añadir que se trata de una forma indirecta, sí, de alguna manera encubierta, de crear costumbre, pues se pretende elevar a rango universal por vías particulares (bilaterales) lo que en el ámbito más próximo al universal (el multilateral) enfrenta se-

105 A la fecha, Estados Unidos ha celebrado este tipo de acuerdos, también denominados "acuerdos PSI" con ocho países. http://www.state.gov/t/isn/c10390.htm.

$106 C f r$. Benvenisti, Eyal y Downs, George W., op. cit., nota 99, p. 616.

107 Der Spiegel, núm. 35, del 25 de agosto de 2008 (la traducción es mía).

108 Ibidem, p. 611. Es cierto que la CIJ recientemente negó la existencia de una nueva costumbre internacional respecto al ejercicio de la protección diplomática por substitución, i. e., el principio según el cual el Estado de la nacionalidad de los accionistas puede ejercer, de forma excepcional, la protección en aquellos casos en los que la sociedad tenga la nacionalidad del Estado cuya responsabilidad es invocada. No obstante, los hechos de que la República de Guinea viera, inter alia, en los APPRI una prueba de la cristalización de una nueva costumbre en la materia, y que la propia Corte destacara que tal cristalización no ha ocurrido, "al menos al momento presente", denotan la tendencia hacia la evolución mencionada. Por otro lado, cabe recordar que la Corte reconoció un régimen especial de protección de inversiones. En dicho régimen, los tribunales arbitrales especializados bien pueden aplicar principios y costumbres reflejados en la multiplicidad de acuerdos bilaterales vigentes, haciéndolos extensivos a no signatarios. Cfr. case Concerning Ahmadou Sadio Diallo, op. cit., nota 51, párrs. 76-95. 
rias dificultades. Dicho de otro modo, la ley especial es transformada "por debajo del agua" en derecho internacional general.

La segunda táctica se refiere, en primera instancia, a la creciente tendencia por parte de ciertos Estados o pequeños grupos de Estados poderosos de abandonar temporalmente o amenazar con abandonar las vías institucionales, cuando éstas se opongan a sus intereses más inmediatos. Este abandono no tiene que ser formal y en ocasiones se muestra incluso mediante una sutil preferencia por vías alternativas. ${ }^{109}$ A consecuencia de ello, las posibilidades de coordinación entre los Estados menos poderosos en las instituciones y los foros multilaterales simplemente pierden importancia. Al mismo tiempo, las burocracias internacionales, incluyendo los tribunales, se ven constantemente amenazados de perder actores clave y contribuyentes importantes. Se trata de una estrategia sumamente eficaz, ya que la fuerza de atracción política y económica de ciertos Estados o grupos de Estados suele conllevar al resto a doblegarse ante los intereses de los primeros. ${ }^{110}$

En ocasiones, ni siquiera es necesario amenazar con la salida de las instituciones. El establecimiento de vías paralelas por parte de Estados poderosos es un reto suficientemente serio, toda vez que su gran capacidad de convocatoria es incuestionable. Un intento reciente en dicho sentido, lo constituye la iniciativa sobre las economías principales, seguridad energética y cambio climático, creada por el gobierno del ex presidente George W. Bush y avalada por el G-8, que reúne a los dieciséis Estados con mayores emisiones de dióxido de carbono per capita, entre ellos México. ${ }^{111}$ Se trata, claramente, de un foro de negociaciones paralelo al pro-

109 Benvenisti, Eyal y Downs, George W., op. cit., nota 99, pp. 614 y ss.

110 Benvenisti y Downs mencionan como claro ejemplo de dicha estrategia el abandono por parte de Estados Unidos y la Unión Europea del GATT durante la Ronda de Uruguay. Al darse cuenta de que no lograrían los resultados deseados en dichas negociaciones, sobre todo respecto a la protección de la propiedad intelectual, se salieron de dicho proceso para negociar entre ellos la OMC, que fue presentada a los demás como un paquete completo y cerrado, incluyendo el Acuerdo sobre los Aspectos de los Derechos de Propiedad Intelectual relacionados con el Comercio (ADPIC). El poder económico de ambos actores fue suficiente para atraer al resto sin dejar mayor alternartiva. Cfr. ibidem, p. 616 .

111 Cfr. G8 Summit, 2007, Heiligendamm, Growth and responsibility in the world economy, Summit Declaration, del 7 de junio de 2007, párr. 53. Para mayor información sobre la iniciativa y las reuniones del Grupo, véase http://www.state.gov/g/oes/climate/ mem/. 
ceso de Naciones Unidas, iniciado formalmente en Bali, en diciembre de 2007 (la ruta hacia Copenhague-2009). No pretendo evaluar aquí si la iniciativa de Washington finalmente se traducirá en un fortalecimiento de la imperante lucha contra el cambio climático; esperemos que así sea. Sin embargo, resulta importante cuestionar la pertinencia y prudencia de fragmentar, mediante el establecimiento de negociaciones paralelas, uno de los procesos más delicados de Naciones Unidas en la actualidad; sobre todo, si tomamos en cuenta que dicha iniciativa proviene de uno de los gobiernos más renuentes a someterse a cualquier tipo de decisión vinculante en la materia.

Una expresión más radical de esta táctica de fragmentación la constituye la salida total de las instituciones y el abandono efectivo de los mecanismos formales del derecho internacional. ${ }^{112}$ La muestra más violenta de ello nos la dio el gobierno de George W. Bush con la coalition of the willing que formó para invadir Irak. Pero el abandono total de las instituciones no tiene que desembocar necesariamente en alianzas bélicas, y el derecho internacional puede ser hecho a un lado sin necesidad de incurrir en la comisión de hechos internacionalmente ilícitos. La táctica a la que nos referimos se presenta constantemente y en los más diversos ámbitos. Benvenisti y Downs identifican cuatro tipos: ${ }^{113}$ la coordinación informal a nivel intergubernamental, $i$. e., las redes gubernamentales de las que habla Anne-Marie Slaughter; ${ }^{114}$ las instituciones no vinculantes y carentes de naturaleza jurídica, a las que podríamos caracterizar como semi-formales; los mecanismos híbridos de cooperación, es decir, entre gobiernos, organismos internacionales y el sector privado; así como la delegación de competencias a instancias netamente privadas, como los denominados standard setting bodies (SSB).

En este juego entran todo tipo de redes transnacionales, así como las coalitions of the willing, típicamente diseñadas al interior de la administración estadounidense, y que van mucho más allá de alianzas milita-

112 Benvenisti, Eyal Downs, George W., op. cit., nota 99, pp. 617 y 618.

113 Cfr. ibidem, p. 618. Dicha tipología ha sido desarrollada por Benvenisti en otros trabajos, véase Benvenisiti, Eyal, op. cit., nota 101, pp. 290-292; id., "Coalitions of the Willing and the Evolution of Informal International Law", en Calliess, Christian et al., Coalitions of the Willing: Avantgarde or Threat?, Göttinger Studien zum Völker-und Europarecht, Munich-Colonia, pp. 2-12.

114 Cfr. Slaughter, Anne-Marie, A New World Order, Princeton, 2004. 
res. ${ }^{115}$ De tal suerte, al lado de las redes informales y semi-formales creadas, por lo general, en las cumbres informales de los Estados más poderosos (G-10, G-7 y G-8), como el Grupo de Acción Financiera (GAFI) y el Comité de Basilea, nos encontramos con mecanismos diseñados en los departamentos administrativos del gobierno estadounidense, como es el caso de las diversas coaliciones en materia de no proliferación de ADM y combate al terrorismo (PSI; Container Security Initiative, CSI; Global Initiative to Combat Nuclear Terrorism, GICNT, y demás). Dichas redes y coaliciones están destinadas a la persecución eficaz de algunos de los intereses más vitales de los Estados poderosos, como la estabilidad de los mercados financieros y la lucha contra el terrorismo. ${ }^{116}$ En vez de recurrir a instituciones establecidas o a foros y mecanismos formales, en los cuales habría que enfrentarse a difíciles y tardadas negociaciones multilaterales, dichos Estados prefieren acuerdos políticos inter se y ad hoc. Caso por caso, se decide si y en qué medida otros Estados son invitados a participar, pero independientemente de ello, las decisiones allí tomadas deben llegar a todos los destinatarios necesarios.

Estos mecanismos amorfos de regulación global son a los que se refiere la CDI en su informe final sobre fragmentación, al mencionar que "un examen de la medida en que los nuevos tipos de "derecho mundial" pueden estar surgiendo fuera del ámbito del derecho internacional estado-céntrico tradicional requeriría un estudio de diferente naturaleza". ${ }^{117}$ Con ello, la CDI sugiere que los mismos tienen características distintas a los demás regímenes especiales de derecho internacional abordados en su informe, pero, al mismo tiempo, los ubica dentro del fenómeno de la fragmentación, es decir, les atribuye propiedades fragmentarias. Interesante resulta la constatación de que éstos surgen "fuera del ámbito del derecho internacional". Si bien la CDI se limita a lo dicho y, de hecho, menciona que las soluciones identificadas para los conflictos normativos derivados de los regímenes y las leyes especiales pueden ser útiles "para

115 Sobre los desafíos que presentan estas redes y coaliciones para el derecho internacional, véase Benvenisti, Eyal, op. cit., nota 113, pp. 1-23; así como Rodiles, Alejandro, "Coalitions of the Willing: coyuntura, contexto y propiedades. Un primer esbozo", Anuario Mexicano de Derecho Internacional, vol. VII, 2007, pp. 675-702.

116 Para un primer intento de diferenciación entre redes transnacionales y coalitions of the willing, véase Rodiles, Alejandro, idem.

117 A/CN.4/L.682, párr. 490. 
encauzar y controlar también esas pautas de regulación oficiosa", 118 este pasaje apunta hacia un fenómeno que merece mayor atención. Me refiero a la posible aparición de "regímenes autónomos propiamente dichos", es decir, de conjuntos de mecanismos que se salen por completo del sistema del derecho internacional $-\mathrm{y}$ del derecho en general - al generar una serie de normas no vinculantes a escala global mediante instancias de toma de decisión informales, flexibles y excluyentes. Es cierto que dicha observación requiere de un análisis detallado, que la pertinencia del término "régimen" es cuestionable desde la teoría social de sistemas, y que incluso podría argumentarse que en la medida que está fuera del sistema no generan conflictos con las normas del mismo. Empero, la evidente incidencia que tienen los estándares, recomendaciones y guías de conducta en el derecho internacional y transnacional, ${ }^{119}$ permite que los mecanismos que los emiten sean considerados como serias amenazas a la coherencia y estabilidad del orden jurídico internacional.

Después de describir las cuatro tácticas, Benvenisti y Downs esbozan algunas estrategias destinadas a frenar y revertir la fragmentación del derecho internacional en el sentido por ellos descrita. ${ }^{120}$ Se trata de algunas tácticas emergentes y de otras eventuales a cargo de Estados menos poderosos, pero especialmente de los Estados democráticos más representativos del mundo en desarrollo, como Brasil, India y Sudáfrica. ${ }^{121}$ Éstas van desde las políticas de apoyo a las instituciones multilaterales, pasando por las negociaciones coordinadas entre ellos y, en ciertos casos, también con organizaciones no gubernamentales (ONG), hasta desarrollos incipientes de lo que podría desembocar en contra-coaliciones (los autores hablan de anti-fragmentation coalition), es decir, en coaliciones entre poderes emergentes, cuya finalidad consistiría en mitigar los efectos fragmentarios de las coaliciones y redes de los Estados dominantes.

\section{Idem.}

119 Los trabajos de la escuela del derecho administrativo global versan precisamente sobre los mecanismos de regulación global y su impacto en los derechos internacional y transnacional. Para un estudio de introducción en español, véase Kingsbury, Benedict et al., El surgimiento del derecho administrativo global, Res Publica Argentina, 2007-3, pp. 25-74. Disponible en http://www.iilj.org/GAL/docu ments/kingsburykrischstewart.pdf.

120 Cfr. Benvenisti, Eyal y Downs, George W., op. cit., nota 99, pp. 619-630.

121 Para Benvenisti y Downs el hecho de que se trate de democracias es importante, pues, según ellos, es más probable que este tipo de coordinación se efectúe entre Estados con un mayor grado de apertura interior. Véase ibidem, p. 619. 
Dichos desarrollos, que de alguna manera podrían describirse como "nuevos esquemas de cooperación sur-sur", tienen el potencial de darle un giro totalmente inesperado al fenómeno de la fragmentación del derecho internacional. En efecto, es aquí donde veo probabilidades reales de darle un enfoque distinto al derecho internacional contemporáneo, que retome con mayor fidelidad las ópticas de los menos poderosos, en el sentido descrito por Okafor. ${ }^{122}$ No obstante, es importante recordar que se trata de evoluciones recientes, por lo que es necesario observarlas con cautela en los próximos años antes de anticiparse a cualquier conclusión. Por su parte, la cuestión acerca de la perspectiva de nuestro país en el debate sobre la fragmentación adquiere nuevas dimensiones ante estas evoluciones, pues ahora ya no sólo se trata de la perspectiva desde México, sino también del papel que México debería asumir dentro de dichos desarrollos.

\section{LA FRAGMENTACIÓN Y MÉXICO. ALGUNAS REFLEXIONES FINALES}

Resulta importante mencionar - aunque sea algo bastante obvioque en las siguientes líneas no se pretende desarrollar la perspectiva de México. Queda claro que ello, en todo caso, tendría que ser el resultado de un debate más amplio al interior de nuestro país. Ni siquiera se presentará la postura del gobierno de México sobre el tema, pues sería bastante artificial extraer de unos cuantos pronunciamientos en foros multilaterales una visión definitiva. Simplemente se harán algunas reflexiones respecto al debate que antecede desde un punto de vista que intentará reflejar las realidades mexicanas, esperando que ello sirva para futuros diálogos.

Nuestras delegaciones en Nueva York nunca realizaron una intervención específica sobre la fragmentación del derecho internacional en el marco de los debates anuales del Informe de la CDI. ${ }^{123} \mathrm{Y}$ ello no se debe a un desdén por un tema, cuya importancia siempre se supo valorar en la

122 Ibidem, pp. 24 y 25.

123 Pronunciamientos sobre el tema figuran, no obstante, en algunas intervenciones de México realizadas en el marco de otros debates como el "Informe Anual de la CIJ" y el "Estado de derecho en los planos nacional e internacional". En las siguientes líneas nos referiremos a dichas intervenciones. 
cancillería, sino más bien a un problema muy concreto y común entre la mayoría de los Estados miembros de Naciones Unidas: no todas las misiones, ni todas las consultorías jurídicas cuentan con los mismos recursos. ${ }^{124}$ Mientras los Estados más desarrollados tienen una infraestrucutra que les permite cubrir toda reunión en Nueva York, Ginebra y Viena al mismo tiempo, y sus delegados ante los diferentes comisiones y comités pueden darse el lujo de llevar sólo unos cuantos temas y especializarse en los mismos, la mayoría de los Estados se ve en la necesidad de atender los más diversos temas con sólo unos cuantos delegados. México ocupa una posición intermedia que le permite tener una presencia activa, no hay duda. Aun así, un país como el nuestro se ve forzado a concentrarse en ciertos rubros y desatender otros. Y hace bien, pues sólo así se garantiza una cobertura adecuada de las prioridades de la política exterior nacional.

Ahora bien, lo que podría explicar la ausencia de una intervención de México sobre la fragmentación del derecho internacional — queda claro que otros temas respecto a los cuales nuestras delegaciones han mostrado un seguimiento constante, como la protección diplomática, la expulsión de extranjeros o la misma responsabilidad del Estado, son de especial importancia para México - muestra, irónicamente, uno de los riesgos inherentes a la misma. La diversificación de regímenes normativos e institucionales y la alta especialización técnica de los mismos podrían ser considerados factores que por sí mismos, es decir, independientemente de que se les considere estrategias de poder o no, dificultan un acceso equitativo a los mecanismos mundiales de toma decisión. Está claro que entre menos recursos e infraestructura tenga un Estado, menores serán sus capacidades de participar en dichos regímenes. Aquí es importante mencionar que si bien ello se manifiesta y repercute en primera instancia a nivel gubernamental, no se limita a él, toda vez que en dichos regímenes o subsistemas intervienen cada vez más ONG, así como los sectores académico y privado. Y, lamentablemente, el desarrollo de dichos sectores, sobre todo de los primeros dos, también refleja una gran asimetría entre los países más desarrollados y los demás. Al reconocer que "la

124 Para una comparación de las estructuras y organización de las consultorías jurídicas de algunos países, véase la base de datos del Consejo de Europa, en http://www.coe. int/t/e/legal_affairs/legal_co-operation/public_international_law/office_of_legal_affairs/ Introduction\%20OLA\%20Database\%20E.asp. 
fragmentación cuestiona la coherencia del derecho internacional", la propia CDI admite que el trato equitativo de los Estados es uno de los puntos críticos del debate, aunque inmediatamente después minimiza cualquier riesgo serio al respecto. ${ }^{125}$

Para México, como para cualquier otro Estado, hay dos maneras de contemplar dichas dificultades: la inmediata o pragmática, por un lado, y la normativa, es decir, aquella que reflexiona sobre las consecuencias a largo plazo para el derecho y la comunidad internacionales. Desde un punto de vista pragmático, tenemos que cuestionarnos qué tan preparado está nuestro país para hacer frente a esta situación. Me parece que el panorama no justifica ninguna señal de alarma. México tiene una buena presencia en los foros internacionales y su diversificación, especialmente la de los tribunales, puede, incluso, representar oportunidades para defender mejor los intereses nacionales en las instancias más adecuadas. Ello explica que nuestros representantes hayan mostrado optimismo ante la proliferación de órganos judiciales internacionales, pues de ellos se espera un desarrollo normativo y una aplicación más equitativa del derecho internacional. México ve en ellos instrumentos que se ha dado la comunidad internacional a sí misma y confía en que, en virtud de competencias bien delimitadas, los posibles conflictos entre ellos no se desborden. Asimismo, ha expresado esperanzas en que el incipiente diálogo judicial internacional se convierta en una herramienta más para garantizar la coherencia necesaria del orden jurídico internacional. ${ }^{126}$

No obstante, dicho optimismo fundado no debería perder de vista que la proliferación de instancias internacionales puede llegar a dificultar la coordinación de posiciones y estrategias a largo plazo, tanto a nivel interno, $i$. e., entre los diferentes sectores involucrados e interesados en el país, como en el plano internacional. Que la proliferación de tribunales internacionales no represente un motivo de preocupación para México es perfectamente razonable, pero no olvidemos que en la regulación global, especialmente en el ámbito transnacional, intervienen cada vez más coaliciones y redes amorfas en las que México ni tiene garantizada su parti-

125 A/CN.4/L.682, párrs. 491 y ss.

126 Para estos argumentos, consúltense las intervenciones de los embajadores de México, Juan Manuel Gómez Robledo y Joel Hernández, en el marco de los informes de la CIJ, en 2006 y 2007, respectivamente, http://www.un.int/mexico/2006/interv_102606.htm y http://www.un.int/mexico/2007/interv_110107b.htm. 
cipación y si llega a ser invitado, generalmente las reglas del juego ya están bien definidas antes de su llegada. Simplemente piénsese en el ingreso de México al GAFI, en 2000. ${ }^{127}$

Así, debe destacarse la excelente intervención de la India en el marco de los trabajos sobre el "Estado de derecho en los planos nacional e internacional", en la Sexta Comisión de la Asamblea General de Naciones Unidas (AGNU), en 2006. En primer lugar, el delegado indio habla de nuevas tendencias en el derecho internacional, entre las cuales ubica a las normas no vinculantes que desempeñan "un papel significativo en el desarrollo del derecho internacional contemporáneo y en los esfuerzos por enmendarlo". ${ }^{128}$ No hay duda, las repercusiones de la regulación global, en sus más diversas y no siempre claras manifestaciones, representan desafíos para el futuro rol del derecho internacional. Inmediatamente después, el representante de la India se refiere a la gama de instancias universales y regionales encargadas de temas de derecho del mar, subrayando el riesgo de que a consecuencia de ello se superpongan sus competencias y se dificulte la cooperación y coordinación. ${ }^{129}$

A la luz de las estrategias descritas anteriormente, ${ }^{130}$ las inquietudes expresadas por la India deberían ser tomadas en serio en un país como México que requerirá, cada vez en mayor medida, de una intensa coordinación con las democracias más representativas del mundo en desarrollo, especialmente con Brasil, pero también con Sudáfrica y la India. Por supuesto que la peculiar situación geopolítica de México nos obliga a recorrer nuestro propio camino, pero ello no debería soslayar las oportunidades que se le están abriendo a los denominados poderes emergentes en las reconfiguraciones de un mundo multipolar o, quizá, no polar. ${ }^{131}$

Dentro de esta primera perspectiva, pero con las miradas puestas al interior de la sociedad mexicana, la fragmentación resulta sumamente in-

127 Sobre la participación de México en el GAFI, véase Rodiles, Alejandro, op . cit., nota 113 , pp. 696-699.

128 Intervención del delegado de la India, Sr. Anwar, durante la séptima sesión de la Sexta Comisión. Cfr. A/C.6/61/SR.7, párr. 78. Énfasis añadido.

129 Cfr. ibidem, párr. 79.

130 Véase, supra, II, D, c.

131 Me refiero a la interesante tesis de Richard N. Haass respecto a que a las reconfiguraciones del orden mundial apuntan hacia una era carente de poderes predominantes, $\mathrm{o}$ bien, hacia un mundo no polar. Cfr. Haass, Richard N., "The Age of Nonpolarity. What Will Follow us Dominance", Foreign Affairs, vol. 87, núm. 3, http://www.foreignaffairs. org/20080501faessay87304/richard-n-haass/the-age-of-nonpolarity.html. 
teresante para México debido a la pluralidad de los temas globales que lo involucran y afectan. Ello convierte a los regímenes especiales que defienden con gran ímpetu la racionalidad de sus causas en vías idóneas para los defensores de dichas causas al interior de nuestro país. Pensando en la determinación con la que persiguen sus fines los regímenes de derechos humanos o del medio ambiente, o bien, las posibilidades que se ventilan en una todavía insuficiente, pero creciente agenda de protección y promoción internacional de los derechos de los pueblos indígenas, podría decirse que la fragmentación ofrece oportunidades para los distintos México, y que corresponde a los sectores interesados en México coordinarse para explorar y explotar esas oportunidades. No olvidemos: la fragmentación es un epifenómeno de la globalización. En la medida en que la fragmentación refleja una pluralidad global, México, como mosaico de culturas e intereses, es un candidato muy atractivo para dichos procesos globales. Pero así como no hay que alarmar en vano ni menospreciar las potencialidades de nuestro país, tampoco hay que caer en un optimismo falaz que pretende que las condiciones para una participación plural de sujetos, abierta y democrática, a nivel global están dadas, al tiempo que oculta que los procesos de fragmentación también incluyen estrategias de poder al más puro estilo del divide et impera.

Finalmente, México debe cuestionarse, desde la perspectiva normativa, qué papel espera del derecho en las relaciones internacionales y transnacionales. Si bien esta pregunta merecería un estudio separado, la postura de México al respecto ha sido tan clara que bien podemos esbozarla aquí.

Independientemente de la conveniencia o no de haber incluido los principios fundamentales del derecho de gentes en la Constitución mexicana, ${ }^{132}$ más clara muestra del papel primordial que ocupa el derecho internacional en la política exterior mexicana no podría haber. Ello se hace aún más evidente si consideramos que el artículo 89, fracción X, no es una mera declaración de intenciones, sino una prescripción concreta para el presidente de la República en la conducción de la política exterior. ${ }^{133}$ De tal suerte, no es una exageración decir que el respeto irrestricto al de-

132 Al respecto, véase Gómez-Robledo Verduzco, Alfonso, "La política exterior mexicana: sus principios fundamentales", Anuario Mexicano de Derecho Internacional, t. I, 2001, pp. 197-217.

133 Constitución Política de los Estados Unidos Mexicanos, México, 2008. 
recho internacional es el principio rector en las relaciones internacionales de México. Y en ese mismo sentido debe interpretarse la reciente inclusión del tema del "Estado de derecho en los planos nacional e internacional" en la Sexta Comisión de AGNU, que responde a una iniciativa conjunta de México y Liechtenstein. ${ }^{134}$

Dicha postura se debe a que México entiende a la comunidad internacional principalmente como un proceso de inclusión y equidad. Las condiciones para una participación inclusiva y equitativa de los más diversos Estados las brinda el derecho internacional mediante su esfera objetiva de validez, i. e., por medio de pautas objetivas de comportamiento, establecidas en virtud de procesos formales, transparentes y previsibles. Para México, la viabilidad de la comunidad internacional como proyecto histórico universal radica en la construcción permanente de una comunidad de derecho. Si bien lo dicho podría tacharse de excesivamente formalista y utópicamente kantiano, no olvidemos que el aparentemente anacrónico formalismo jurídico sigue siendo la única vía que garantiza previsibilidad y seguridad para los actores menos poderosos en el orden internacional. Y la utopía kantiana ha permitido la construcción de los mínimos denominadores comúnes que sostienen a una comunidad internacional que, a pesar de todas sus carencias, sigue siendo la fuente de legitimidad más clara y funcional tanto para los Estados menos como para los más poderosos. En dicho sentido, no hay duda, la tradición diplomática, la cultura jurídica y la realidad política internacional de México nos acercan al constitucionalismo del derecho internacional en el debate sobre la fragmentación. ${ }^{135}$

Lo anterior no debe ser confundido con un legalismo cerrado que ignore nuevas evoluciones y no cuestione la viabilidad de sus propios mecanismos. Por supuesto que el derecho internacional requiere cambios importantes para hacer frente a las amenazas globales. La tradición mediadora de su diplomacia, su postura de acercamiento en los foros multilaterales y su considerable peso en Latinoamérica, hacen de México un actor clave para realizar dichos cambios. La diplomacia mexicana debe enfocarse a desempeñar ese papel en la reconfiguración de las reglas del juego, pero exigiendo siempre que se respeten las reglas de cambio del jue-

134 Cfr. A/61/142, Carta de fecha 11 de mayo de 2006 dirigida al secretario general por los representantes permanentes de Liechtenstein y México ante las Naciones Unidas.

135 Ibidem, pp. 16-19. 
go. El quebrantamiento de dichas reglas a favor de un cambio más rápido y eficaz quebrantaría nuestras propias reglas y nos colocaría en una situación de incertidumbre estratégica a largo plazo.

La CDI menciona en su Informe que "[1] os conflictos entre regímenes especializados pueden superarse por medio del derecho, aunque el derecho no vaya mucho más allá de exigir la disposición a escuchar a otros, tener en cuenta sus puntos de vista y encontrar una solución razonada al final". ${ }^{136}$ Me parece que en México podemos concordar con la opinión de la CDI, aunque por acá diríamos que, justamente gracias a su disposición a escuchar a otros, el derecho internacional representa con mayor fidelidad las expectativas de la comunidad internacional en su conjunto, y que, en cuanto a dichas expectativas, va mucho más allá de lo que jamás puedan llegar aquellos mecanismos novedosos y eficientes, basados en la división y en la maximización de su propia racionalidad. 